\title{
Local-Scale Urban Energy Balance Observation under Various Sky Conditions in a Humid Subtropical Region
}

\author{
YuRONG SHI, YufENG ZHANG, AND RiYI Li \\ State Key Laboratory of Subtropical Building Science, Department of Architecture, South China University of \\ Technology, Wushan, Guangzhou, China
}

(Manuscript received 23 October 2018, in final form 15 May 2019)

\begin{abstract}
The present study presents local-scale urban energy balance observations under various sky conditions in a humid subtropical region. The study site is a typical urban residential area in Guangzhou in which building density is $38 \%$, vegetation coverage is $36 \%$, and mean building height is $21 \mathrm{~m}$. The observation was conducted at a 110-m-high tower using the eddy covariance technique from September to November 2016. The median diurnal pattern and daily maxima were achieved for all radiation components and turbulent fluxes. The Bowen ratio $(\beta)$ results indicated a predominant role for sensible heat flux $\left(Q_{H}\right)$ in the daytime and latent heat flux $\left(Q_{E}\right)$ at night. The sky conditions played a significant part in the urban surface energy exchanges, showing that the median daily maxima of net radiation $\left(Q^{*}\right), Q_{H}$, storage heat flux $\left(\Delta Q_{S}\right)$, surface albedo, and $\beta$ all present a consistent order from large to small for clear, cloudy, and rainy days and a different order of rainy, clear, and cloudy days for $Q_{E}$. The mean daytime $Q_{H} / Q^{*}, Q_{E} / Q^{*}, \Delta Q_{S} / Q^{*}$, and $\beta$ changed with urban density, while $Q_{E} / Q^{*}$ and $\beta$ also varied with vegetation fraction. Furthermore, the adaptability of net all-wave radiation parameterization (NARP), objective hysteresis model (OHM), and local-scale urban meteorological parameterization scheme (LUMPS) were validated, given the index of agreements of 0.998 and 0.951 for $Q^{*}$ and $\Delta Q_{S}$ and the reasonable RMSEs for $Q_{H}$ and $Q_{E}$. The present study helps to verify and improve the parameterizations of energy exchange over an urban surface in the humid subtropical region.
\end{abstract}

\section{Introduction}

In the humid subtropical region of China, urban climate dramatically changes with the fast urbanization of the region, and the changes have significant effects on urban heat island intensity, building energy consumption, and people's living environment. There are three horizontal scales in urban climate studies (Oke 2006): microscale, local-scale, and mesoscale, with spatial scales of $1-10^{3}, 10^{3}-10^{4}$, and $10^{4}-10^{5} \mathrm{~m}$, respectively. The local-scale urban neighborhoods with many human activities were our primary focus. Surface energy exchanges are the key to understanding the local-scale urban climate, and field observations of surface energy balance (SEB) are the most direct and objective way to study them.

Energy balance observations cannot only observe local energy flux changes with long periods but can also be used to verify the accuracy of a large number of energy balance models. Currently, the turbulent fluxes of sensible and latent heat have been widely observed using

Corresponding author: Yufeng Zhang, zhangyuf@scut.edu.cn the eddy covariance (EC) technique, the predominant method in the Flux Network (FLUXNET; Baldocchi et al. 2001), with a well-established theory (Campbell and Norman 1998; Lee et al. 2006). The measured terms include the components of net all-wave radiation and turbulent fluxes of sensible and latent heat, which are the major parts of the urban energy balance equation.

Virtually all observed and modeled estimates of the components of the energy balance of urban surfaces have been made since 1970 (Arnfield 2003). Recently, the majority of urban SEB observations were conducted in Europe and North America (e.g., Grimmond and Oke 2002; Nemitz et al. 2002; Christen and Vogt 2004; Velasco et al. 2011; Goldbach and Kuttler 2013; Chow et al. 2014; Kotthaus and Grimmond 2014a,b), while only a few were conducted in Asia (e.g., Moriwaki and Kanda 2004; Liu et al. 2012; Miao et al. 2012; Ao et al. 2016a; Ando and Ueyama 2017; Roth et al. 2017). Several studies focused on the (sub)tropical regions that are reviewed by Tejeda-Martínez and Jáuregui-Ostos (2005) as well as Roth (2007), for instance, the one by Velasco et al. (2011) and Roth et al. (2017). However, 
very limited studies have been conducted in the humid subtropical climate regions (Cfa, classified by Köppen climate classification), including those in Shanghai, China (Ao et al. 2016a), Tokyo, Japan (Moriwaki and Kanda 2004), and Sakai, Japan (Ando and Ueyama 2017). Furthermore, there is a dearth of robustly measured SEB data from dense urban core areas with local climate zone 1 (LCZ 1) (Stewart and Oke 2012), according to the review by Oke et al. (2017).

A large number of sophisticated urban energy balance models have been created and developed for understanding the process of surface energy exchanges, for example, the local-scale urban meteorological parameterization scheme (LUMPS) (Grimmond and Oke 2002), the improved mesoscale model (Martilli et al. 2002) and the SEB model (Pape and Löffler 2004), the surface urban energy and water balance scheme (SUEWS) (Järvi et al. 2011; Ward et al. 2016), and others. Grimmond et al. $(2010,2011)$ have reviewed and compared a large number of urban energy balance models. The urban energy balance model has clear physical significance and properties of portability and universality, which is a preferred method to analyze the local-scale urban climate. The results of energy balance observations help us to verify and improve parameterizations of energy exchange over complex urban surfaces (Christen and Vogt 2004).

LUMPS formulates in the framework of SEB of

$$
Q^{*}=Q_{H}+Q_{E}+\Delta Q_{S}
$$

where $Q^{*}$ is net all-wave radiation, $Q_{H}$ and $Q_{E}$ are sensible and latent heat flux, and $\Delta Q_{S}$ is storage heat flux. It was proposed initially by Grimmond and Oke (2002) with some limitations on not including anthropogenic heat $\left(Q_{F}\right)$ and requiring $Q^{*}$ as an input parameter. The scheme was greatly improved afterward by Loridan et al. (2011), with the improvements on combining the net all-wave radiation parameterization (NARP) (Offerle et al. 2003) to calculate $Q^{*}$, and taking the influences of $Q_{F}$, vegetation phenology, and water availability into account. LUMPS is the focus of this study as it is one of the simplest urban SEB models and has a good performance with an input of only a few parameters from standard meteorological observations along with the necessary information on urban surface cover.

Guangzhou is a typical city in the humid subtropical region of China, with a hot-humid climate and diverse sky conditions. The objectives of the present study undertaken in Guangzhou are 1) to observe the temporal characteristics of local-scale urban energy balance exchanges under various sky conditions and 2) to validate the adaptability of LUMPS in the humid subtropical region. This observation is novel in that it comes from the humid subtropical climate region from which more research is required, and also in that it provides the measured SEB data for the compact high-rise LCZ. Moreover, the validation of LUMPS with the observed radiation and turbulence fluxes is expected to enhance knowledge of urban SEB and provide an essential base for urban planning and resilience designs in humid subtropical regions.

\section{Methods}

\section{a. Climate and site}

The present study was conducted in Guangzhou, with the city center located at latitude $23^{\circ} 08^{\prime} \mathrm{N}$ and longitude $113^{\circ} 19^{\prime} \mathrm{E}$. It is a typical megacity in the humid subtropical region of China (Fig. 1a). The long summers are hot and humid, with abundant rainfall, and winters are temperate and short. On average over 30 years (from 1981 to 2010), the monthly mean temperature is $26.9^{\circ} \mathrm{C}$, the relative humidity (RH) is $75 \%$ for summer (from April to October), and those values are $17.9^{\circ} \mathrm{C}$ and $64 \%$, respectively, for autumn (from November to December). Guangzhou is in the monsoon region, which experiences prevailing southeast winds in summer and north winds in winter. The annual sunshine time is approximately from 1500 to $2000 \mathrm{~h}$. The yearly rainfall is around $1801 \mathrm{~mm}$. All meteorological conditions are based on data provided by the National Meteorological Information Center (http:// data.cma.cn/). Summer, with extremely hot and humid weather, is the most important season for the city. The total population exceeded 14 million, with a population density of 1883 people per square kilometer, at the end of 2016, based on data provided by the Statistical Bureau of Guangzhou (http://www.gzstats.gov.cn/).

According to the LCZ concept of Stewart and Oke (2012), we made a LCZ classification map of Guangzhou using the World Urban Database and Access Portal Tools (WUDAPT), as shown in Fig. 1b. The center of Guangzhou, which is an urban area with impervious roads, buildings, and scattered trees, was mainly classified into two LCZ types: a compact high-rise LCZ and a compact midrise LCZ (LCZ 1 and LCZ 2, respectively). When compared to an older classification for Guangzhou available from the WUDAPT website (http://www.wudapt.org/), our results show that, with rapid urbanization, the LCZ types for Guangzhou have shifted to the top levels with higher and more intensive buildings. We chose the west part of the Haizhu district in Guangzhou as the study site, that is, the area of $1-\mathrm{km}$ radius around the tower as 

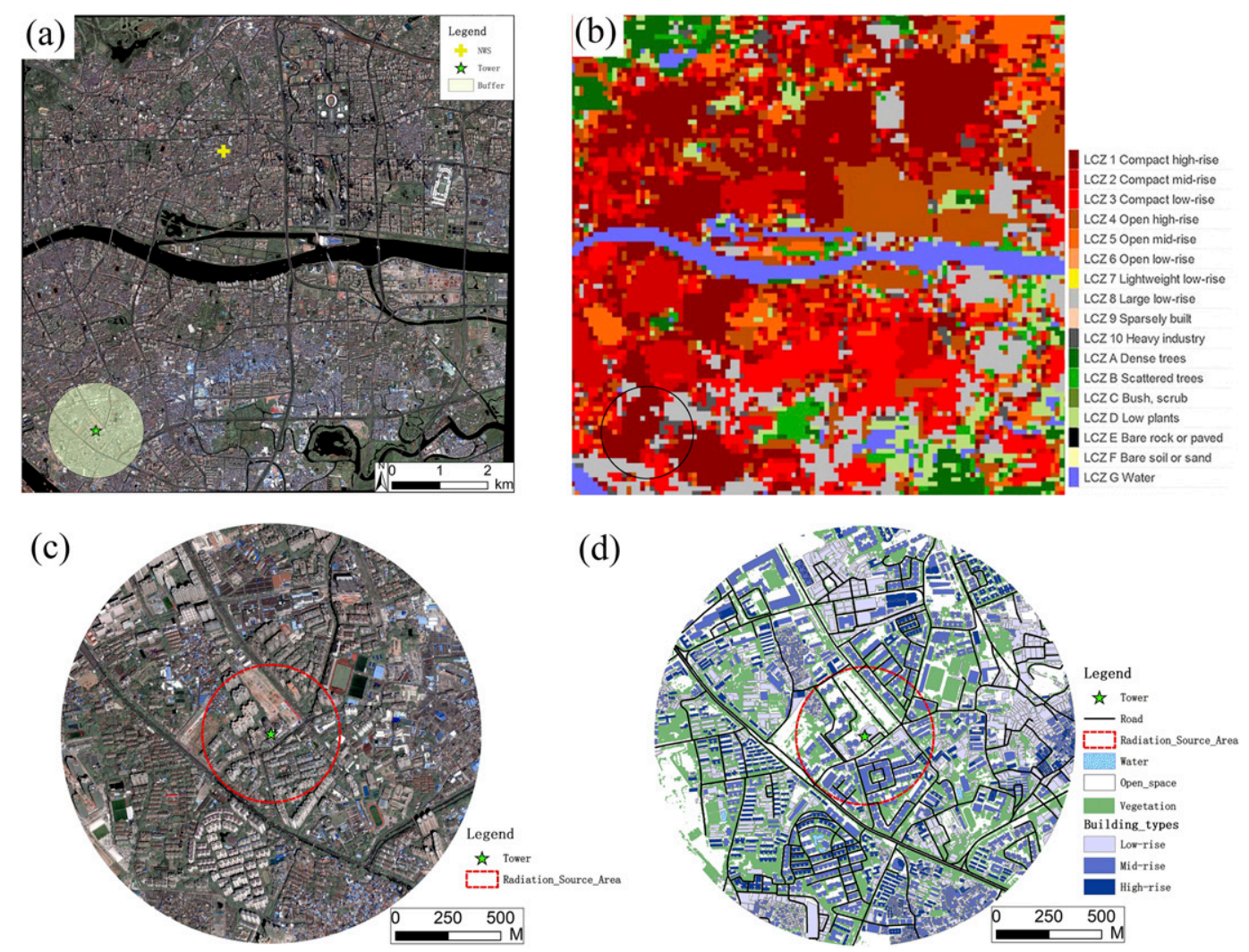

FIG. 1. (a) Visible image map and (b) LCZ classification map of Guangzhou and (c) visible image map and (d) land classification map of the studied site. The visible image map was obtained by the GeoEye-1 satellite on 22 Oct 2017. The land classification map is based on the GIS database, with a 1-km radius centered on the high tower (green star in the map) at the study site.

Fig. 1c shows, which contains the two LCZ types of central Guangzhou.

The study site is a typical local-scale urban residential area in which several main neighborhoods are made up of high-rise buildings that are compactly arranged; the site is considered LCZ 1. Moreover, the LCZ subclass is LCZ 8 , so the study area could be defined as $\mathrm{LCZ} 1_{8}$. According to the detailed GIS database (see Fig. 1d), the building density is $38 \%$, the mean building height is $21 \mathrm{~m}$, and the vegetation coverage is $36 \%$ for the whole study site. The building height separated into three types: low-rise (1-3 stories), midrise (3-9 stories), and high-rise buildings (above 9 stories), according to the classification of Stewart and Oke (2012). The green spaces are continuously distributed, with dense tree cover in the neighborhoods and sparse tree cover along the roads. The buildings' exterior surfaces are mainly light-color tiles, and a few are plaster. The roadways are covered by asphalt.

\section{b. Data collection and processing}

The energy exchange measurements were conducted at the top of a high tower. The high tower is located at the center of the study site $\left(23^{\circ} 04^{\prime} 44^{\prime \prime} \mathrm{N}, 113^{\circ} 16^{\prime} 12^{\prime \prime} \mathrm{E}\right.$; see Fig. 1), is $25 \mathrm{~m}$ high and stands on the roof of a 28 -story building with a width of $21 \mathrm{~m}$ (Fig. 2a). The choice of the tower meets the requirements of World Meteorological Organization (2008), which suggested that the measurements should be raised at least one building width above the top when the instruments are placed on top of a building. Moreover, the tower is a frame structure without an external wall, so the effect of the tower on the measurements could be ignored.

Three components of urban SEB were measured: net all-wave radiation, turbulent fluxes of sensible and latent heat. A net radiometer (NR01) (Table 1) was used to measure the net all-wave radiation $Q^{*}$, including incoming shortwave radiation $(K \downarrow)$, reflected shortwave radiation $(K \uparrow)$, incoming longwave radiation $(L \downarrow)$, and outgoing longwave radiation $(L \uparrow)$, at 1-min intervals. The turbulent sensible and latent heat fluxes were measured using the EC method; see Campbell and Norman (1998) for more details on the method. The EC system consisted of a sonic anemometer and an open path infrared gas analyzer, both of which were made by 

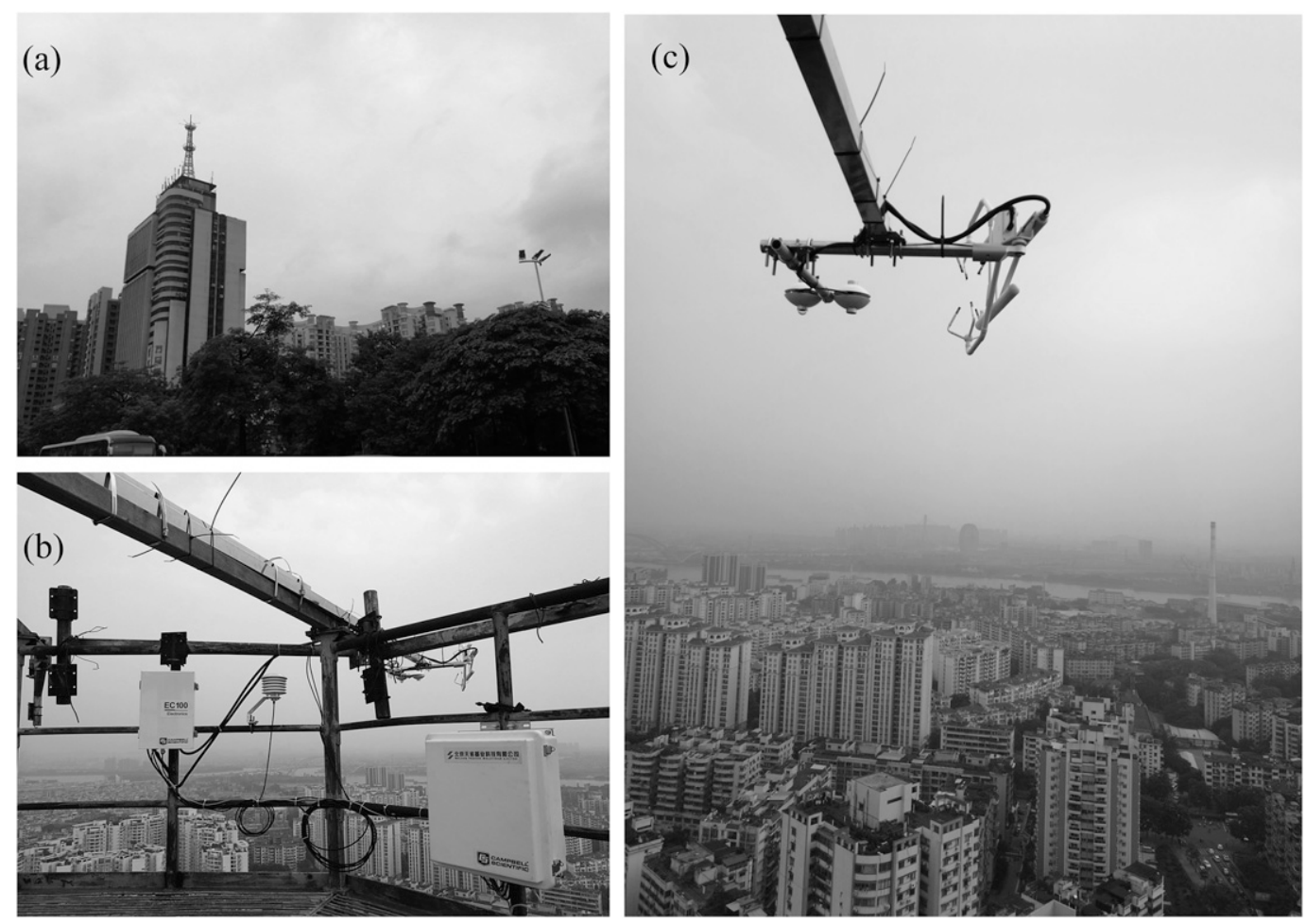

FIG. 2. (a) The high tower, (b) recording system, and (c) instruments.

Campbell Scientific and sampled at $10 \mathrm{~Hz}$, as shown in Table 1 and Figs. 2b and 2c.

All the instruments were mounted on a stand extending $2 \mathrm{~m}$ from the edge of the high tower in the south direction (the net radiometer was projected toward the right south direction, and the sonic anemometer and open path infrared gas analyzer were oriented southeast-northwest, see Figs. 2b,c) and were connected to a datalogger (CR3000, Campbell Scientific). The measurement point height was $110 \mathrm{~m}$ above the ground level, which equates to a ratio of 5.2 of the mean building height $Z_{h}$ of the study site and falls in the inertial sublayer.

The observations were conducted continuously in three months from 11 September to 28 November 2016.
The method by Zhang (1934) that is nationally acknowledged and adopted by the Chinese standard QX/T 152-2012 was used for season classification. It takes the local pentad-average air temperature as criterion, a period of that temperature larger than $22^{\circ} \mathrm{C}$ as summer and that temperature from $10^{\circ}$ to $22^{\circ} \mathrm{C}$ as spring or autumn. The average air temperatures are $26.8^{\circ}$ and $25.2^{\circ} \mathrm{C}$ for September and October, respectively, and it was higher than $22^{\circ} \mathrm{C}$ even on many days in November. Accordingly, the study period is identified as two months of summer and one month of autumn, which are the representative seasons for the humid subtropical climate regions. It is worth mentioning that the study year 2016 was wetter when comparing with the average climate pattern in over 30 years.

TABLE 1. Instrumentations for radiation and turbulent fluxes.

\begin{tabular}{|c|c|c|c|c|c|}
\hline Measured content & Instrument & Model & Manufacturer & Precision and (measurement range) & Sample \\
\hline Net radiation & Net radiometer & NR01 & Hukseflux & For daily sums: $\pm 10 \%\left(0-2000 \mathrm{~W} \mathrm{~m}^{-2}\right)$ & $1 \mathrm{~min}$ \\
\hline \multirow[t]{3}{*}{ Sensible and latent heat flux } & Sonic anemometer & CSAT3A & Campbell & $\begin{array}{l}U_{x}: 1 \mathrm{~mm} \mathrm{~s}^{-1}\left( \pm 30 \mathrm{~m} \mathrm{~s}^{-1}\right) \\
U_{y}: 1 \mathrm{~mm} \mathrm{~s}^{-1}\left( \pm 60 \mathrm{~m} \mathrm{~s}^{-1}\right) \\
U_{z}: 0.5 \mathrm{~mm} \mathrm{~s}^{-1}\left( \pm 8 \mathrm{~m} \mathrm{~s}^{-1}\right) \\
\text { Wind direction: } 0.6^{\circ}\left( \pm 170^{\circ}\right) \\
\text { Sonic temperature: } 0.025^{\circ} \mathrm{C}\left(-50^{\circ} \text { to }+60^{\circ} \mathrm{C}\right)\end{array}$ & $10 \mathrm{~Hz}$ \\
\hline & Gas analyzer & EC150 & Campbell & $\mathrm{H}_{2} \mathrm{O}: 0.006 \mathrm{mmol} \mathrm{mol}^{-1}\left(0-72 \mathrm{mmol} \mathrm{mol}^{-1}\right)$ & $10 \mathrm{~Hz}$ \\
\hline & Ambient temperature & 100K6A1IA & BetaTherm & $\pm 0.15^{\circ} \mathrm{C}\left(-30^{\circ}\right.$ to $\left.+50^{\circ} \mathrm{C}\right)$ & $10 \mathrm{~Hz}$ \\
\hline
\end{tabular}


The data analysis was performed based on 30-min block averages and using Beijing time that is $8 \mathrm{~h}$ later than coordinated universal time (UTC). We discarded the data during rainfall and the subsequent 30 -min period, according to Kotthaus and Grimmond (2012, 2014a). Before calculating half-hourly covariance, some necessary data corrections were applied, including spiking of raw data (Vickers and Mahrt 1997), double rotation (Kaimal and Finnigan 1994), sonic temperature (Schotanus et al. 1983), and theoretical highfrequency spectral (Massman 2000) and crosswind (Liu et al. 2001) corrections; the water vapor was also corrected for density fluctuations (Webb et al. 1980). Data quality was estimated using two tests: the steady-state test and the developed turbulent conditions test (Foken et al. 2004), and the data that did not pass these tests were eliminated.

The meteorological conditions observed at the National Weather Station (NWS) of Guangzhou $\left(23^{\circ} 07^{\prime} 48^{\prime \prime} \mathrm{N}\right.$, $113^{\circ} 17^{\prime} 24^{\prime \prime} \mathrm{E}$, the height is $72 \mathrm{~m}$ above sea level, and approximately $6 \mathrm{~km}$ from the study site; see Fig. 1a) in 2016 were obtained. The NWS was surrounded by the compact midrise and high-rise buildings, which is similar to the surroundings of the study site. These are considered representative of the atmospheric conditions in the central area of Guangzhou and could be used as the reference of the study site. The parameters included air temperature, relative humidity, shortwave radiation, precipitation, wind speed, and wind direction.

\section{c. Data classification and availability}

We used a bulk daily shortwave transmission $\left(\tau_{\text {day }}\right)$ to classify the sky conditions as clear, rainy, and cloudy:

$$
\tau_{\text {day }}=K_{\downarrow \text {,day }} / G_{0}
$$

where $K_{\downarrow \text {,day }}$ is the daily total downward shortwave radiation at the measurement height; $G_{0}$ is daily total solar radiation at the top of the atmosphere, calculated referring to Ao et al. (2016b).

According to Dou et al. (2019), Kawai and Kanda (2010), and Duffie and Beckman (2013), if $\tau_{\text {day }}$ was larger than 0.50 , the day was classified as a clear day. If any rainfall was recorded at the meteorological station, the day was classified as a rainy day. The remaining days were classified as cloudy days.

The availability of data for different sky conditions is shown in Table 2 . The availability of radiation data is $89 \%$ for all the study days, and data loss is mainly caused by insufficient power supply for the instruments. The availability of turbulence data is $61 \%$, where $30 \%$ of data are missing because of the low voltage of instruments, and $9 \%$ of data are missing because of the rain's impact.
TABLE 2. Data availability for different sky conditions by the days.

\begin{tabular}{llccc}
\hline \hline \multirow{2}{*}{ Class } & \multicolumn{4}{c}{ Days for radiation data (for turbulence data) } \\
\cline { 2 - 5 } & Sep & Oct & Nov & Total \\
\hline All days & $20(21)$ & $31(12)$ & $28(28)$ & $79(61)$ \\
Clear days & $11(9)$ & $6(0)$ & $1(1)$ & $18(10)$ \\
Rainy days & $3(8)$ & $14(6)$ & $10(10)$ & $27(24)$ \\
Cloudy days & $6(4)$ & $11(6)$ & $17(17)$ & $34(27)$ \\
\hline
\end{tabular}

\section{d. Source area calculations}

The radiation source area is for the radiometer, and the turbulence source area is for the thermometer, hygrometer, gas analyzer, and sonic anemometer (Oke 2006). The two kinds of source areas usually differ: the radiation source area is, in general, a circular patch with the radiometer at the center, whereas the turbulence source area is an ellipse in a planar view, with the instruments always outside the area.

\section{1) RADIATION SOURCE AREA}

For the Lambertian surfaces, the radiation source area is mainly a function of radiometer height. Schmid et al. (1991) provided an equation to acquire the radius $(r)$ of the radiation source area:

$$
r=Z_{1}\left(\frac{1}{F}-1\right)^{-0.5}
$$

where $F$ is the view factor, and $Z_{1}$ is the height of the radiometer.

\section{2) Turbulence SOURCE AREA}

After Schmid and Oke (1990) proposed the definition of turbulence source area (also called footprint), many models have been proposed: the scalar Flux Source Area Model (FSAM) by Schmid (1994, 1997), the footprint model by Kormann and Meixner (2001), and the footprint flux prediction (FFP) model by Kljun et al. (2015). In the present study, the FFP model was adopted to estimate the turbulence source area as the model was developed to analyze the long-term series.

In the FFP model, the required input parameters include $Z_{m}=Z-Z_{d}$ ( $Z$ is the sensor measurement height, and $Z_{d}$ is the zero-plane displacement height), roughness length $Z_{0}$, boundary layer height $h$, Obukhov length $L$, friction velocity $u_{*}$, wind speed and direction, and the standard deviation of lateral velocity fluctuations $\sigma_{v}$. The turbulence source area will be larger with a higher $Z_{m}$, a lower $Z_{0}$, a larger mean wind speed, a higher $h$, a smaller $\sigma_{v}$, or a smaller $u_{*}$ according to Kljun et al. (2015).

Most of the needed parameters were derived directly from the measured data, except for $Z_{m}, Z_{0}$, and $h$. 


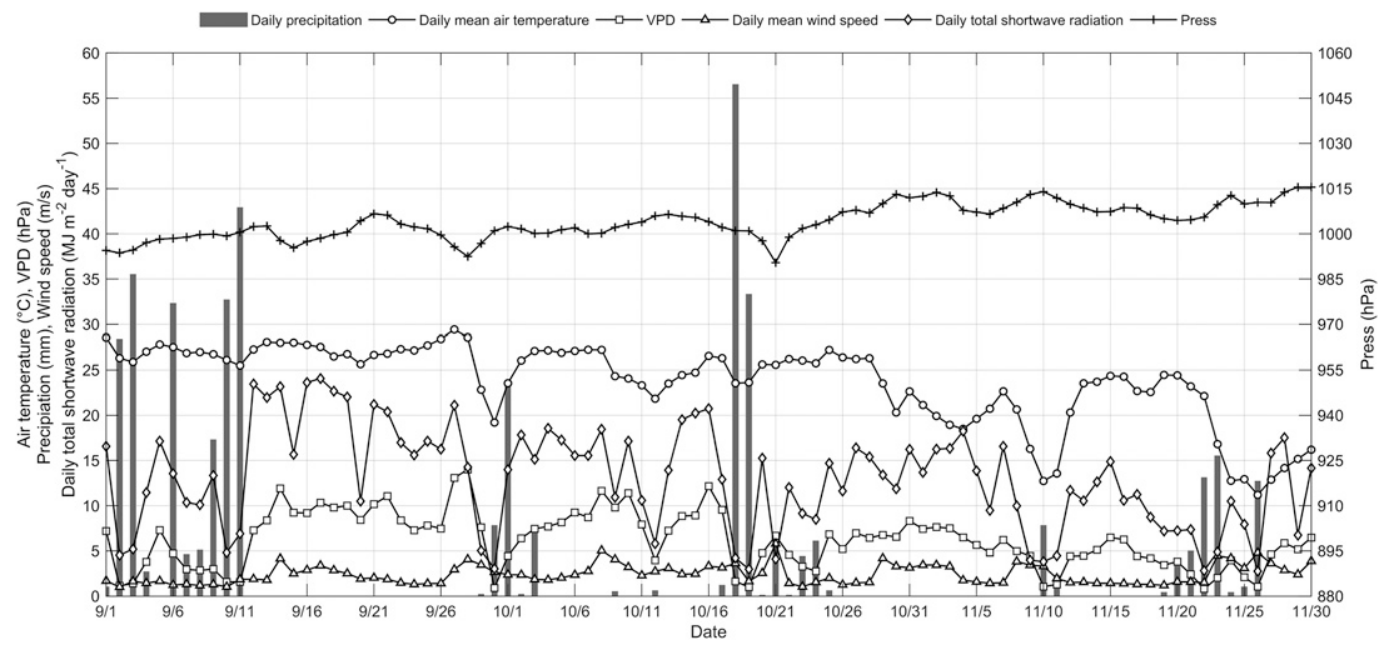

FIG. 3. Daily meteorological conditions during the study period. The parameters are mean values except for the precipitation and shortwave radiation, which are the cumulative values.

Among these, $Z_{0}$ and $Z_{d}$ were estimated using the GIS database together with morphometric methods. There are some morphometric methods based on mean building height $Z_{h}$, plan area fraction $\lambda_{p}$, and frontal area index $\lambda_{f}$ such as those in Macdonald et al. (1998), Raupach (1994), and Bottema (1995, 1997). Grimmond and Oke (1999a) reviewed them and suggested a rank order for these methods. The method of Macdonald et al. (1998) was adopted in the present study because it is applicable across the full range of building densities. The input parameters of $Z_{h}, \lambda_{p}$, and $\lambda_{f}$ were acquired based on the GeoEye-1 stereo satellite imagery with a $0.41-\mathrm{m}$ resolution, as shown in Fig. 1d. The $h$ was calculated for the neutral to stable and convective conditions separately, in which the interpolation formula of Nieuwstadt (1981) was used for the former and the slab model of Batchvarova and Gryning (1991) based on a simplified turbulence kinetic energy (TKE) equation was used for the latter.

\section{Results and discussion}

\section{a. Meteorological conditions}

The daily meteorological conditions at the NWS are shown in Fig. 3, and the monthly mean values are presented in Table 3. The air temperature and shortwave radiation declined month by month and within the most comfortable range for human outdoor activities.

The monthly mean relative humidities were all approximately $80 \%$. The cumulative precipitation decreased significantly month by month. It can be further observed in Fig. 3 that the daily mean vapor pressure deficit (VPD) was positively related to air temperature and negatively related to precipitation.

The wind frequency distribution at the NWS and the study site are shown in Fig. 4. Both sites are within the height of the inertial sublayer and have the same surroundings, so the NWS could be treated as the reference of the study site. The wind speeds ranged from 0 to $6.9 \mathrm{~m} \mathrm{~s}^{-1}$ and averaged $2.4 \mathrm{~m} \mathrm{~s}^{-1}$ at the NWS during the study period. The main wind direction observed at the NWS during the study period (Fig. 4a) was quite similar to that in the hottest period from June to August (see Fig. 4b); both have the most prevailing wind direction of north. The wind conditions measured at the study site showed slight differences with those of the NWS: the main wind direction was northwest (Fig. 4c), the timeaverage wind speed was $2.5 \mathrm{~m} \mathrm{~s}^{-1}$, the wind directions in the $270^{\circ}-360^{\circ}$ sector accounted for $45 \%$ of the total

TABLE 3. Monthly meteorological conditions during the study period. The parameters are mean values except for the precipitation, which is the cumulative value.

\begin{tabular}{|c|c|c|c|c|c|c|}
\hline & Air temperature $\left({ }^{\circ} \mathrm{C}\right)$ & Pressure $(\mathrm{hPa})$ & VPD $(\mathrm{hPa})$ & $\begin{array}{c}\text { Daily total shortwave } \\
\text { radiation }\left(\mathrm{MJ} \mathrm{m}^{-2} \mathrm{day}^{-1}\right)\end{array}$ & $\begin{array}{l}\text { Precipitation } \\
\left(\mathrm{mm} \text { month }^{-1}\right)\end{array}$ & Wind speed $\left(\mathrm{m} \mathrm{s}^{-1}\right)$ \\
\hline Sep & 26.8 & 999.30 & 6.99 & 15.07 & 210.5 & 2.06 \\
\hline Oct & 25.2 & 1003.30 & 6.95 & 13.54 & 140.0 & 2.64 \\
\hline Nov & 19.1 & 1009.82 & 4.45 & 10.28 & 61.8 & 2.50 \\
\hline Sep to Nov & 23.7 & 1004.14 & 6.13 & 12.96 & 412.3 & 2.40 \\
\hline
\end{tabular}


(a)

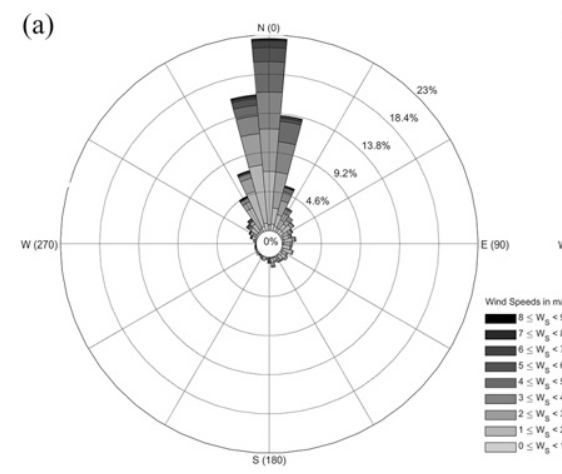

(b)

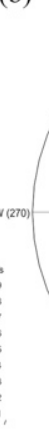

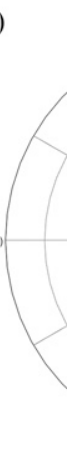

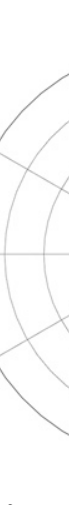

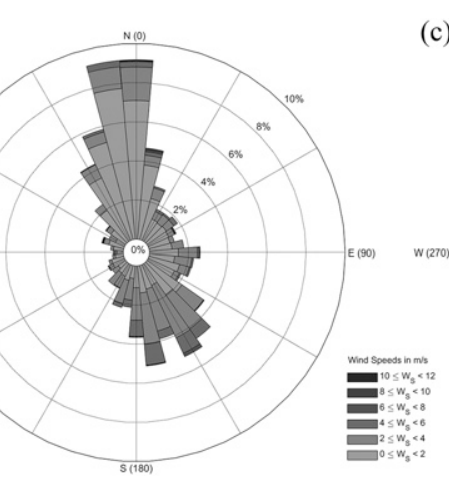

(c)

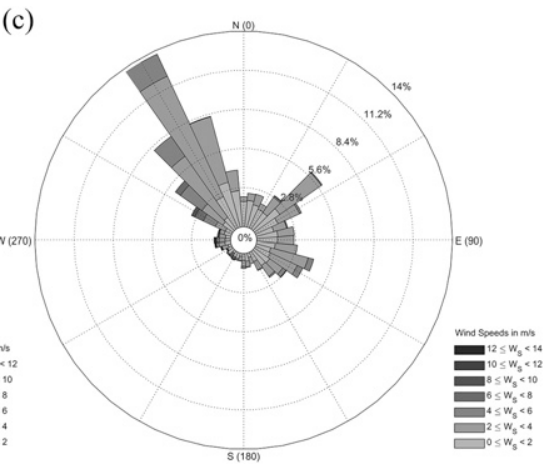

FIG. 4. Wind frequency distribution at (a) the NWS from September to November, (b) NWS from June to August, and (c) the study site from September to November.

sample data, and the low wind speeds ranging from 0 to $4 \mathrm{~m} \mathrm{~s}^{-1}$ accounted for $89 \%$. The wind directions during the measured period were not representative as the prevailing wind direction is southeast over the years.

Many researchers have suggested that atmospheric stability is a major factor for turbulence source area (Kljun et al. 2002; Kormann and Meixner 2001). Atmospheric stability is defined as $\zeta=\left(Z-Z_{d}\right) / L$ and can be divided into three categories: unstable $(\zeta<-0.1)$, near-neutral $(-0.1 \leq \zeta<0.1)$, and stable $(\zeta \geq 0.1)$ conditions (Kotthaus and Grimmond 2014a). The atmospheric stability of the present study is shown in Fig. 5. The unstable condition was dominant during the daytime, and the proportion of the stable and near-neutral conditions at nighttime were much larger than the daytime. The stable condition fraction was relatively small.

\section{b. Modeled source areas}

\section{1) RADIATION SOURCE AREA}

The modeled radiation source area is shown by the red dashed line in Figs. 1c and 1d. The radius $r$ of the radiation source area is $330 \mathrm{~m}$ with the $90 \%$ view factor. Within the radiation source area, the building density is
$34 \%$, and the greening coverage is $33 \%$, both of which are very close to those of the whole study area. As a result, it is confirmed that the measured radiation flux can competently represent the study site situation.

\section{2) TurbulenCE SOURCE AREA}

By using the GIS database of the study site, a series of heights needed for modeling turbulence source area were obtained, as shown in Table $4 ; \lambda_{p}$ is equal to the building density of 0.38 . As the front buildings would block winds to the rear ones in terms of the main wind direction, we merged the nearby buildings into one to acquire a more accurate frontal area. The frontal area in the main wind direction of $315^{\circ}$ was determined to be $1.6 \mathrm{~km}^{2}$, and $\lambda_{f}$ was determined to be 0.52 . These results were substituted into the morphometric method of Macdonald et al. (1998), and $Z_{0}$ and $Z_{d}$ were obtained accordingly.

Knowing the above input parameters, we used the FFP model compiled in MATLAB to model the turbulence source area of the study site, as shown in Fig. 6. It is evident that the source area of the stable and nearneutral condition was more extensive than that of the unstable condition. The areas contributing to $50 \%$ of the
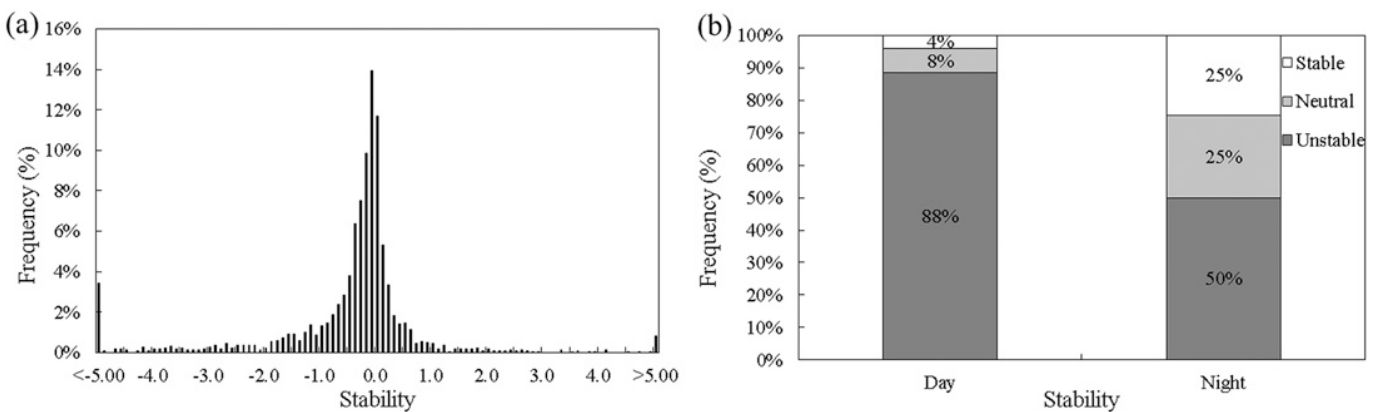

FIG. 5. Atmospheric stability $\zeta$ during the study period, shown as (a) a frequency histogram and as (b) a frequency distribution categorized by time of day and the three stability conditions. 
TABLE 4. Source area characteristics at the study site.

\begin{tabular}{llc}
\hline \hline & \multicolumn{1}{c}{ Source area characteristic } & Value \\
\hline Height (m) & Mean building height $Z_{h}$ & 21 \\
& Roughness length $Z_{0}$ & 2.3 \\
& Displacement height $Z_{d}$ & 13.5 \\
& Sensor height $Z$ & 110 \\
& Height of building hosting tower & 85 \\
& Tower height above the roof & 25 \\
\hline
\end{tabular}

source area were approximately $1000 \mathrm{~m}$ and exceeded $1000 \mathrm{~m}$ in the main northeast wind direction under the two atmospheric conditions. These results are larger than those of Kotthaus and Grimmond (2014b) and Liu et al. (2012), as the measurement height is much higher in the present study.

\section{c. Radiation components}

Radiative flux energy is the most critical sector of the urban SEB. All four components of the radiation budget during the study period are shown in Fig. 7. For a better understanding of the difference with sky conditions, we separated the results into three sky conditions as shown in Fig. 8.

\section{1) SHORTwave RAdiations}

At the study site, the daily maxima of $K \downarrow$ appeared around noon and ranged from nearly 200 to $1000 \mathrm{~W} \mathrm{~m}^{-2}$ during the study period, and the time period, latitude, and sky conditions played crucial roles in that broad range. In the same time period, the range is smaller in London (Kotthaus and Grimmond 2014a,b), where more cloudy days occurred and the daily maxima $K \downarrow$ changed from 200 to $800 \mathrm{~W} \mathrm{~m}^{-2}$, and also in Shanghai (Ao et al. 2016b) and Tokyo (Moriwaki and Kanda 2004), where more clear days occurred and the daily maxima $K \downarrow$ changed from nearly 500 to $870 \mathrm{~W} \mathrm{~m}^{-2}$. It is obvious that the closer to the equator, the larger of the magnitude of $K \downarrow$.

The daily maxima of $K \uparrow$ appeared around noon and ranged from approximately 20 to $120 \mathrm{~W} \mathrm{~m}^{-2}$ during the study period. $K \downarrow$ and $K \uparrow$ presented a similar tendency, and significantly decreased month by month for the clear days while changing slightly with months for the rainy and cloudy days. The lowest values of both $K \downarrow$ and $K \uparrow$ occurred in the rainy days.

\section{2) LONGWAVE RADIATIONS}

At the study site, the daily maxima of both $L \downarrow$ and $L \uparrow$ appeared after noon, showing a noticeable time lag with that of solar radiation; $L \downarrow$ ranged from 280 to $460 \mathrm{~W} \mathrm{~m}^{-2}$, and $L \uparrow$ ranged from 360 to $530 \mathrm{~W} \mathrm{~m}^{-2}$. This confirmed that Oke (1987) indicated that the value of $L \uparrow$ is greater than $L \downarrow$, because the values of surface temperature and emissivity are greater than their atmospheric counterparts. Besides, the value of $L \uparrow$ was more variable than $L \downarrow$ as Fig. 7 shows, probably because the urban surface temperature varied considerably in a day; $L \downarrow$ increased with cloud cover, as the magnitude of $L \downarrow$ on the rainy days was larger than that on the clear and cloudy days. This agrees with Flerchinger et al. (2009), who suggested the variation in $L \downarrow$ is a function of near-surface atmospheric conditions (temperature and humidity) and the presence of mid- or low-level clouds. By comparing Fig. 7 with Fig. 3, it can be seen that the time series of $L \uparrow$ was close to that of
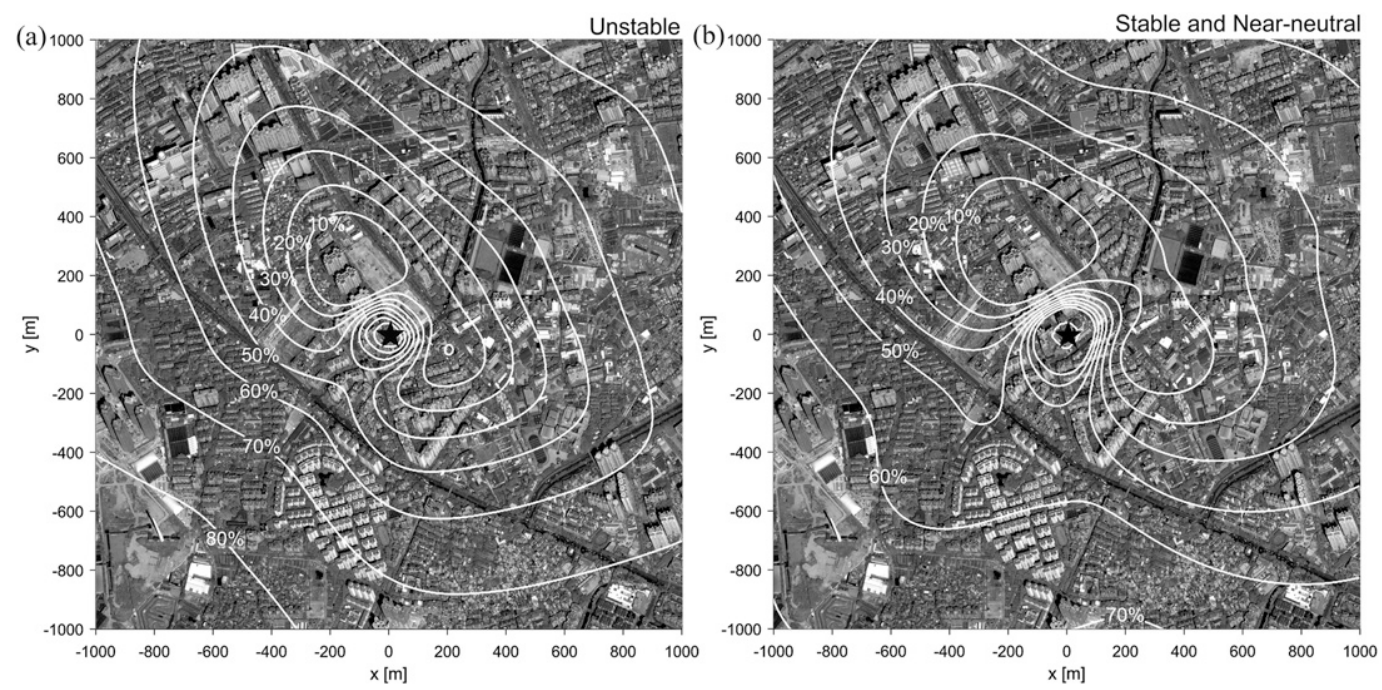

FIG. 6. The turbulence source area of the visible image map for (a) unstable and (b) stable and near-neutral atmospheric stability conditions. 

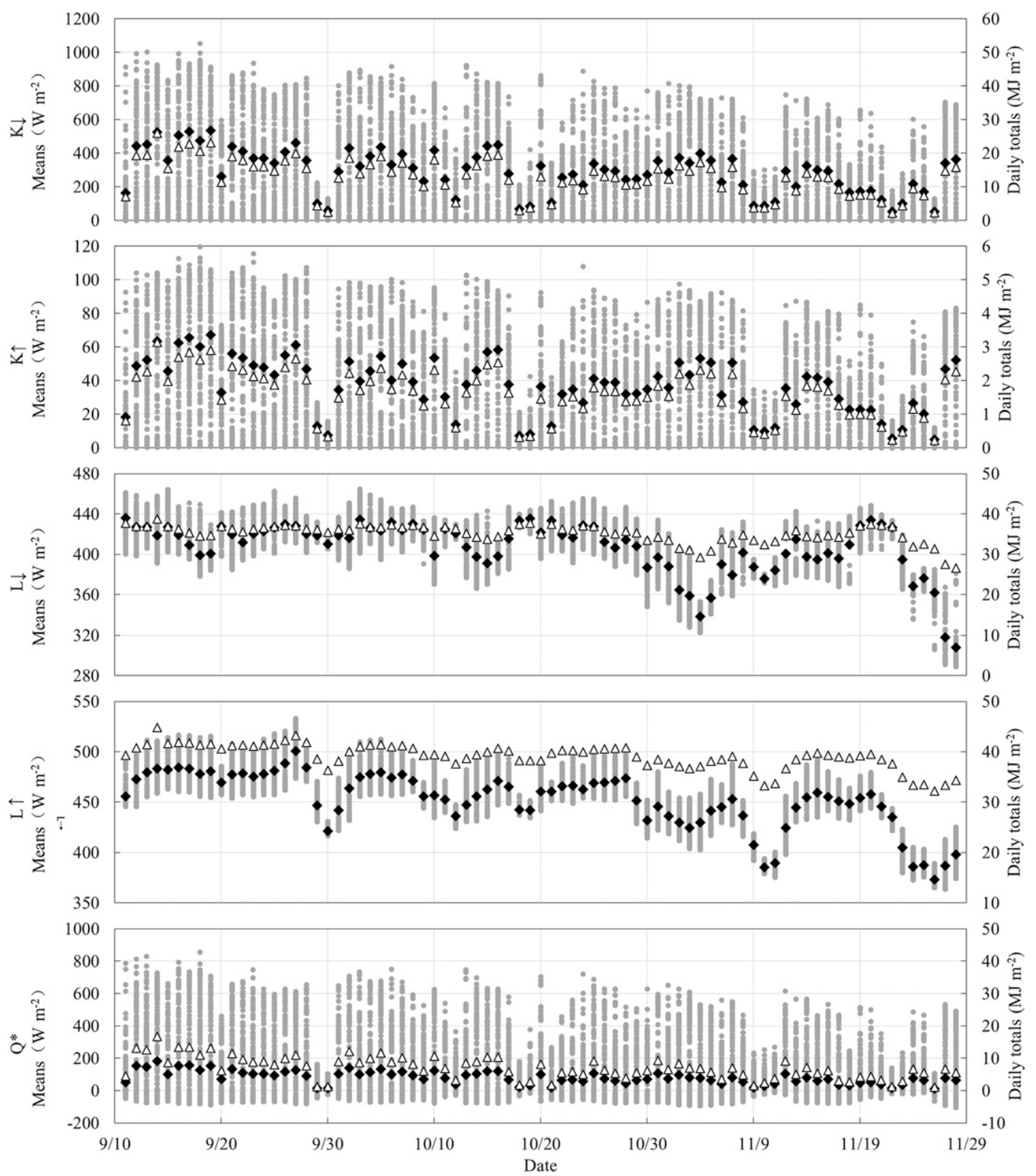

FIG. 7. Observed 10-min average (gray dots) fluxes from the high tower for incoming shortwave radiation $(K \downarrow)$, reflected shortwave radiation $(K \uparrow)$, incoming longwave radiation $(L \downarrow)$, outgoing longwave radiation $(L \uparrow)$, net allwave radiation $\left(Q^{*}\right)$, and its daily means (black diamonds) and daily totals (white triangles). Shortwave radiation is for sunlight hours from 0600 to 1800 , and longwave and net all-wave radiations are for a whole day.

near-surface air temperature, suggesting that the air temperature is affected by the thermal properties of the land surface. This consistency was evident on the clear and cloudy days, but not on the rainy days, as Fig. 8 shows.

The net all-wave radiation $Q^{*}$ combines all four radiative components and is related to the sun's elevation, surface characteristics, cloud cover, and so forth. At the study site, the daily maxima of $Q^{*}$ ranged from 200 to $800 \mathrm{~W} \mathrm{~m}^{-2}$, and the median diurnal pattern of $Q^{*}$ was similar to that of $K \downarrow$ under various sky conditions, except for being negative at nighttime.

\section{3) Surface Albedo}

Surface albedo, as a critical parameter for weather forecasting and climate modeling, determines the energy partition between the surface and atmosphere and influences land surface temperature, evapotranspiration, energy balance, etc. (Liu et al. 2008). The surface albedo was calculated as the ratio of the reflected to 


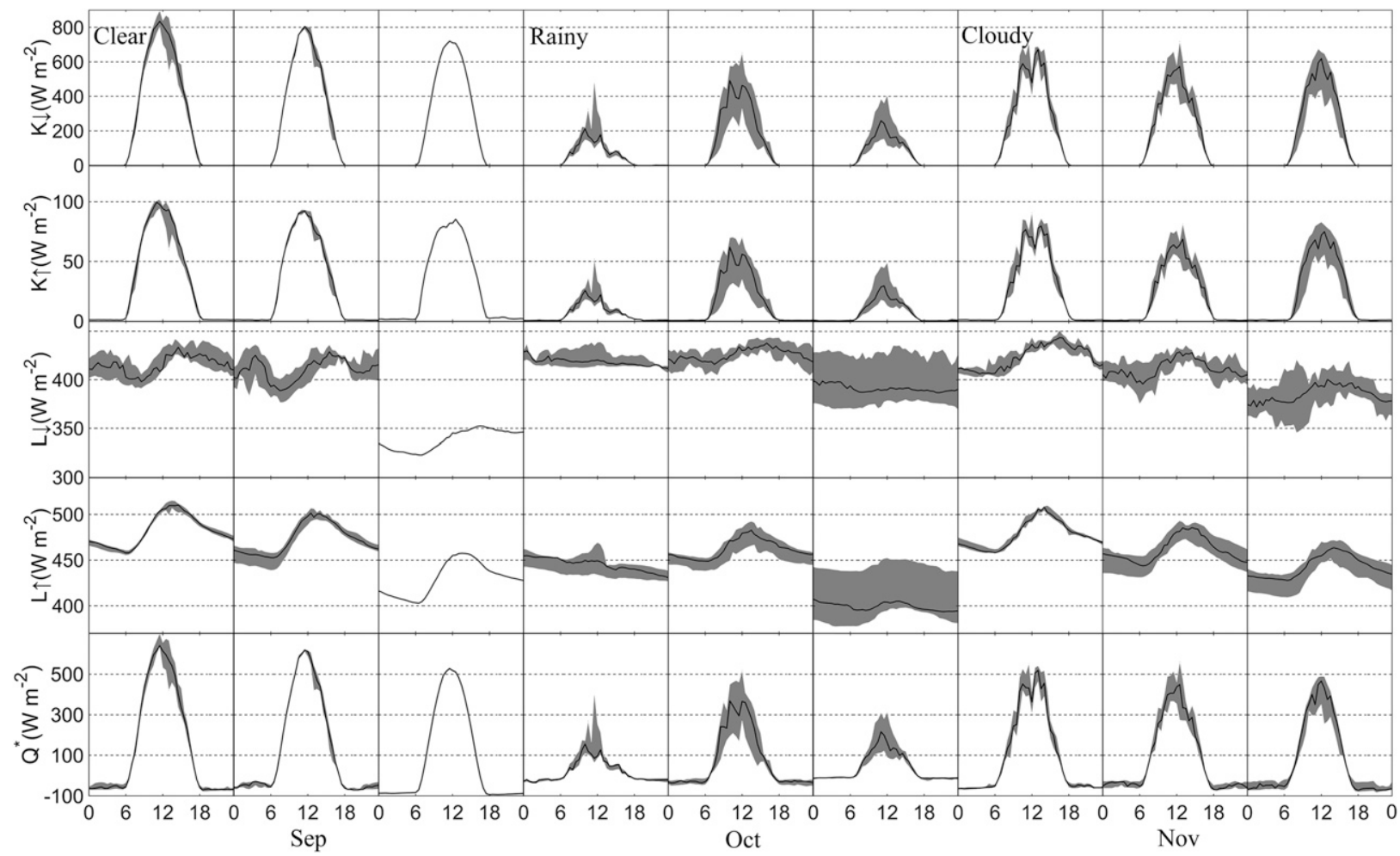

FIG. 8. Median diurnal variation (solid lines) of radiation components under clear, rainy, and cloudy days with interquartile range (IQR, shaded)

incoming solar radiation flux $(\alpha=K \uparrow / K \downarrow)$ under the conditions that both were larger than $2 \mathrm{~W} \mathrm{~m}^{-2}$. The diurnal variation in surface albedo showed a general U-shape pattern, as seen in Fig. 9, with larger values in both early morning and late afternoon and lower values during the rest of the daytime.

The surface albedo values were nearly 0.12 during most times of the day, which corresponds to the large field of view including complicated morphometric configurations and the dark-colored surfaces of road and roofs at the study site. This is close to that of Basel, Switzerland (Christen and Vogt 2004), but far from that of Los Angeles, California, and Chicago, Illinois
(Offerle et al. 2003), most likely because of the morphometric configuration and surface materials. During the periods of early morning and late afternoon, the surface albedo was largest on the clear days, followed by that on the cloudy days, and the albedo on the rainy days was smallest on November, as Fig. 9 shows. This probably was due to the reflection of direct solar radiation caused the large surface albedo, and the direct solar radiation was active on the clear days and weak on the cloudy and rainy days (Lucht et al. 2000).

The variations in median surface albedo with solar elevation and solar azimuth angle and the sun-path diagram of Guangzhou are shown in Fig. 10. The surface
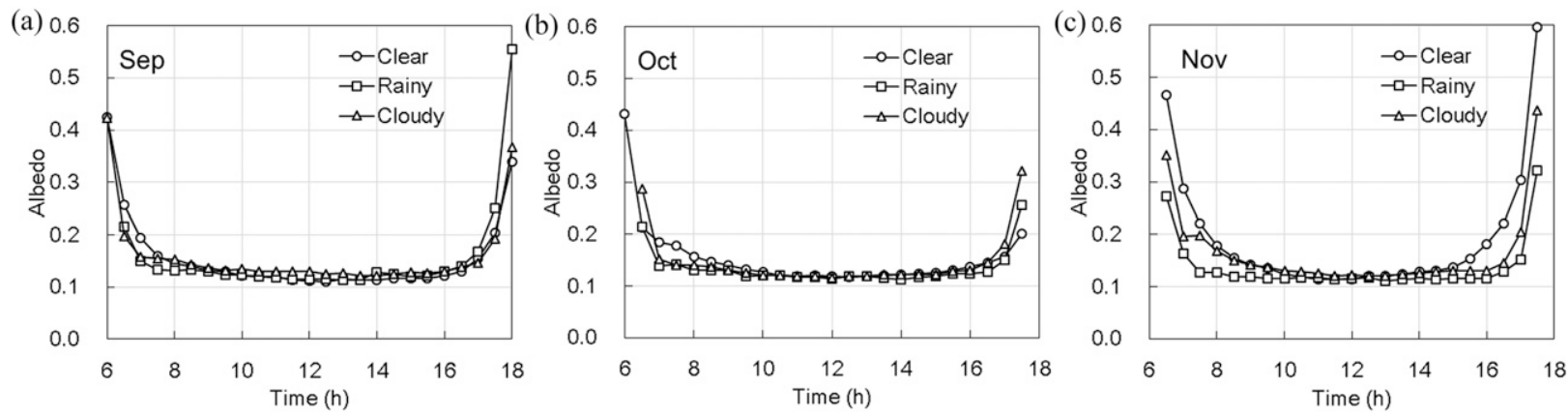

FIG. 9. Median diurnal variation of surface albedo under various sky conditions for three months. 

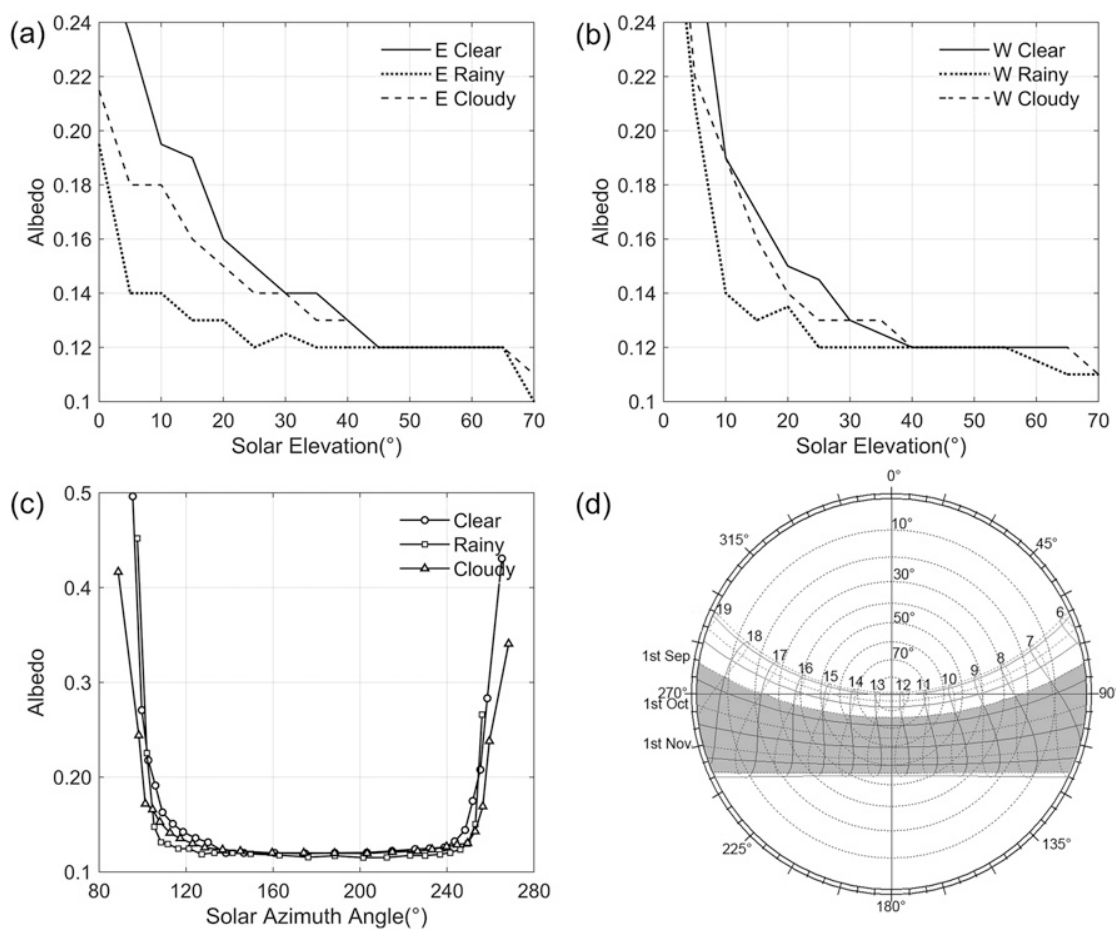

(d)

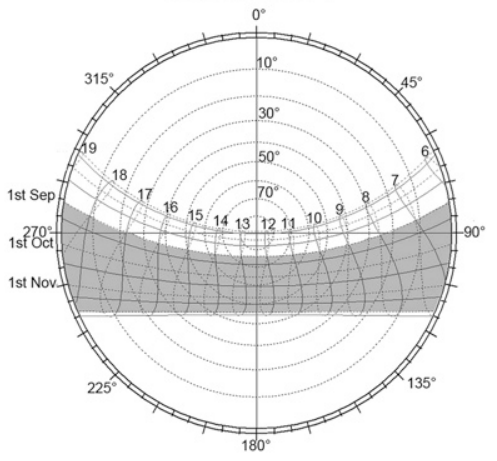

FIG. 10. Median surface albedo as functions of solar elevation angle when (a) the sun is in the east (E), (b) when the sun is in the west (W), and as functions of (c) solar azimuth angle and (d) together with the sun-path diagram of Guangzhou (the shaded area for the study period from September to November).

albedo decreased gradually with the increasing solar elevation, and the gradient was more evident on the clear days (Figs. 10a,b). This corresponds well to the findings of Aida (1982), Kotthaus and Grimmond (2014a,b), and Ao et al. (2016b). The higher surface albedo that occurred at a lower solar elevation was mainly caused by more reflected solar radiation at a smaller angle of incidence. The results also show a greater decreasing slope when the sun was in the west, indicating that the variation in surface albedo was more evident during sunset than at sunrise. This is opposite to the results obtained in London (Kotthaus and Grimmond 2014a,b) and Shanghai (Ao et al. 2016a,b). This can be explained by the heterogeneity around the site. The west direction of study sites in London and Shanghai were covered by a larger fraction of vegetation, while there are more high buildings in the present study. Figure 10c shows an increase from 0.12 to 0.50 when the solar azimuth angle changed from $140^{\circ}$ to $80^{\circ}$ in the early morning or from $240^{\circ}$ to $280^{\circ}$ in the late afternoon, suggesting that the surface albedo apparently varied with solar azimuth.

\section{d. Surface energy exchanges}

The median diurnal patterns of the absolute magnitude of $Q^{*}, Q_{H}, Q_{E}, \Delta Q_{S}$, and Bowen ratio $\beta$ are presented for all days and various sky conditions in Fig. 11. $\Delta Q_{S}$ was calculated as the residual term of the $\mathrm{SEB}$, in which $Q_{F}$ was estimated and added to $Q^{*}$ [see section $3 \mathrm{~d}(2)]$. All the results exhibited a diurnal pattern that is high in the daytime and low in the nighttime.

\section{1) Sensible And Latent HeAt Fluxes}

Sensible heat flux always is a main contributor to energy transport away from the surface into the urban boundary layer (Kotthaus and Grimmond 2014a). From Fig. $11, Q_{H}$ was the largest at $1230,1300,1330$, and 1400 , with median daily maxima of $118,171,72$, and $113 \mathrm{~W} \mathrm{~m}^{-2}$ for the overall, clear, rainy, and cloudy days, respectively. The daytime $Q_{H}$ was largest on the clear days, followed by that on the cloudy days, and the daytime $Q_{H}$ on the rainy days was least, following the same order of the net all-wave radiation. At night, $Q_{H}$ was close to zero on the clear days and rainy days but higher than zero during most of the time on the cloudy days. This result is similar to that observed in London (Kotthaus and Grimmond 2014a) and Basel (Christen and Vogt 2004), where a majority of $Q_{H}$ remained positive during nighttime.

$Q_{E}$ exhibited a smaller diurnal variation than that of $Q_{H}$, with median daily maxima of $66,106,134$, and 
(a) 700
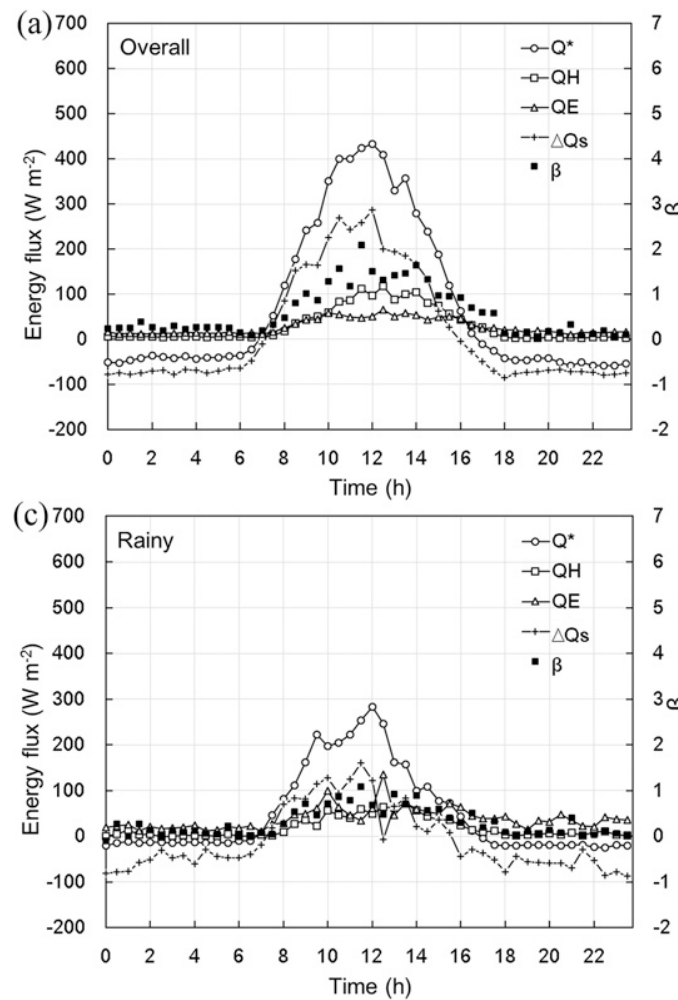
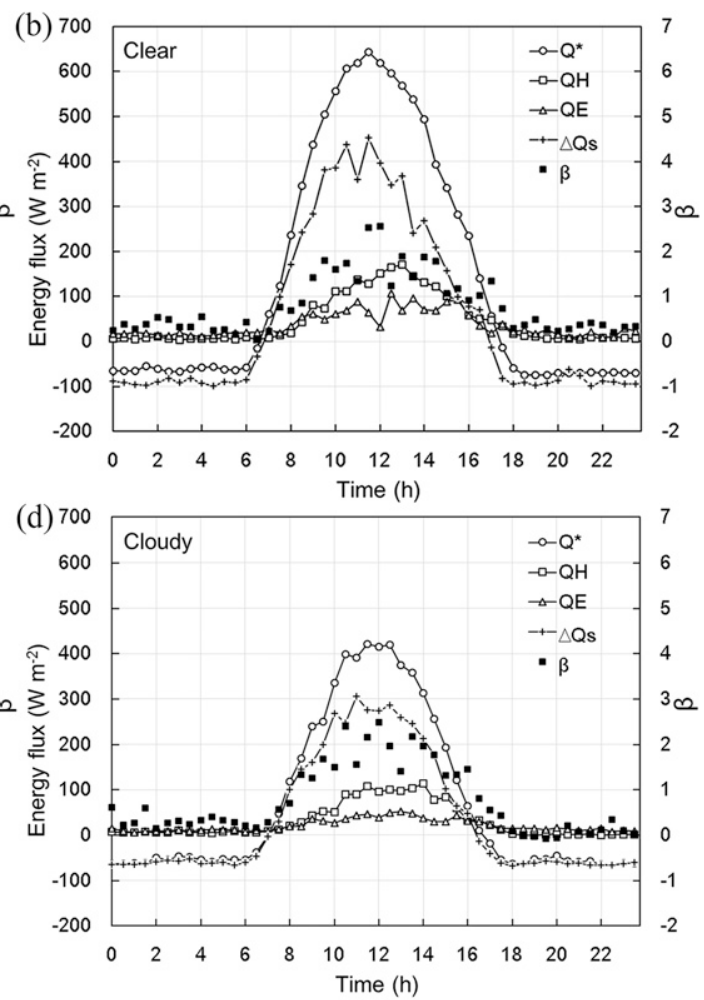

FIG. 11. Median diurnal pattern of net all-wave radiation $\left(Q^{*}\right)$, sensible heat flux $\left(Q_{H}\right)$, latent heat flux $\left(Q_{E}\right)$, storage heat flux $\left(\Delta Q_{S}\right)$, and Bowen ratio $(\beta)$ for (a) all days and various sky conditions of (b) clear, (c) rainy, and (d) cloudy days.

$52 \mathrm{~W} \mathrm{~m}^{-2}$ for the overall, clear, rainy, and cloudy days, respectively, as shown in Fig. 11. The daytime $Q_{E}$ on clear and rainy days was higher than that of the cloudy days; likewise, the nighttime $Q_{E}$ was highest on rainy days, suggesting that strong radiation and high air temperature can promote evaporation, and abundant rainfall can provide more wet surfaces for long-time evaporation.

The daily maxima of median $\beta$ occurred in the daytime, with magnitudes of 2.1,2.6, 1.1, and 2.5 for overall, clear, rainy, and cloudy days, respectively, as shown in Fig. 11. The median values of $\beta$ were larger than one during most of the daytime, indicating that $Q_{H}$ dominated the surface energy exchanges in the daytime, but were lower than one at night, indicating more pronounced evapotranspiration effects and dominant role of $Q_{E}$ at night. The median values of nighttime $\beta$ were higher than zero in most cases. This was mainly caused by the variations of $Q_{H}$ as the nighttime $Q_{E}$ was always positive for all conditions.

\section{2) ANTHropogeniC AND STORAGE HEAT FLUXES}

$Q_{F}$ is substantial and not negligible in the high-rise building residential areas. The large-scale urban consumption of energy (LUCY) model (Allen et al. 2011) was adopted in the present study both for the field observation and LUMPS validation. A fraction of vehicles on the road was assumed as 0.8 and the average speed was $48 \mathrm{~km} \mathrm{~h}^{-1}$. The International Road Federation (IRF) World Road Statistics 2005, Gridded Population of the World (GPW), version 3 (v3), dataset (2005), and energy consumption from a dataset in 2011 were used. Accordingly, the calculation by the LUCY model showed a minimum of $2.0 \mathrm{~W} \mathrm{~m}^{-2}$ at night and a maximum of $11.6 \mathrm{~W} \mathrm{~m}^{-2}$ in the daytime. The mean value of $Q_{F}$ in the study site during the whole study period was estimated as $7.0 \mathrm{~W} \mathrm{~m}^{-2}$.

The median daily maxima of $\Delta Q_{S}$ were $287,453,161$, and $306 \mathrm{~W} \mathrm{~m}^{-2}$ for the overall, clear, rainy, and cloudy days, respectively, as shown in Fig. 11. The average daytime partitioning of $Q^{*}$ dissipated by $\Delta Q_{S}$ was approximately $54 \%$, which is definitely larger than that of $Q_{H}$ and $Q_{E}$ [see details in section 3d(3)], suggesting that the heat gain $Q^{*}$ was mostly dedicated to $\Delta Q_{S}$ both during daytime and nighttime.

\section{3) COMPARISONS WITH OTHER URBAN SITES}

The mean ratios of energy partitioning $\left(Q_{H} / Q^{*}\right.$, $\left.Q_{E} / Q^{*}, \Delta Q_{S} / Q^{*}\right)$ normalized by $Q^{*}$ at the study site are shown in Fig. 12. In the daytime, the majority of energy is partitioned into $\Delta Q_{S}$, followed by $Q_{H}$, and only with a small proportion for $Q_{E}$. 


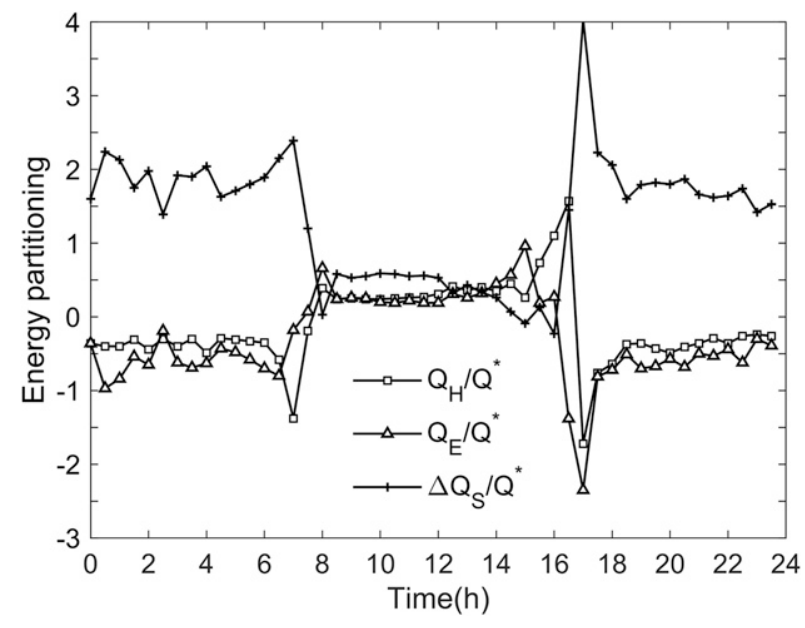

FIG. 12. Flux ratios of energy partitioning $\left(Q_{H} / Q^{*}, Q_{E} / Q^{*}, \Delta Q_{S} / Q^{*}\right)$ normalized by $Q^{*}$.

For better understanding the differences between various urban sites in different climates and the physical meanings of the normalized energy partitioning, we collected a series of SEB observations in the (sub) urban sites in Table 5 in both the (sub)tropical and temperate climate regions. These mean daytime ratios of $Q_{H} / Q^{*}, Q_{E} / Q^{*}, \Delta Q_{S} / Q^{*}$, and $\beta$ are useful to compare other studies with different seasons and different magnitude of $Q^{*}$ forcing. The changes of mean daytime $Q_{H} / Q^{*}, Q_{E} / Q^{*}, \Delta Q_{S} / Q^{*}$, and $\beta$ with vegetation fraction and urban density [expressed as $Z_{h} \lambda_{p}$ (i.e., the product of mean building height and plan area fraction of building)] (Oke et al. 2017) are shown in Fig. 13 for the sites.

In the present study, the average daytime partitioning of $Q^{*}$ (for $Q^{*}>0 \mathrm{~W} \mathrm{~m}^{-2}$ ) into $Q_{H}$ was approximately $33 \%$, which is much smaller than that of the other sites in Table 5. From Fig. 13a it can be seen that the higher the urban density, the lower the ratio of $Q_{H} / Q^{*}$ is. It is true for the daytime, mainly because more heat was stored in the buildings, as the storage heat flux in Fig. 13d shows. The coefficient of determination $R^{2}$ is only 0.28 , indicating that other factors, such as the thermal properties of roof, wall, and road, may play a role in the values of $Q_{H}$ as well.

The average daytime partitioning of $Q^{*}$ into $Q_{E}$ was approximately $21 \%$, which is smaller than that of $Q_{H} / Q^{*}$ and $\Delta Q_{S} / Q^{*}$ in this study. However, this is still larger than that of sites in hot desert climate regions, such as Me98, Me03, and Me06, indicating that $Q_{E}$ accounted for a significant effect on the urban SEB in the humid subtropical regions. From Figs. $13 \mathrm{~b}$ and $13 \mathrm{e}$ it can be seen that the $Q_{E} / Q^{*}$ ratio is a function of both urban density and vegetation fraction. The $Q_{E} / Q^{*}$ increases with the decreasing urban density $\left(R^{2}=0.48\right)$ and increasing vegetation fraction $\left(R^{2}=0.36\right)$.
The mean daytime $\beta$ (2.16) at the study site is similar with that of Ba02u1, Ba02u2, Ob10u, Tk01, Sh13, Ph12, Si06-13, and Tu90, with the values ranged from 1.77 to 2.62, and lower than that of Me93, Me98, and Me06, with the values of 7.4, 4.4, and 2.9, respectively. Figures $13 \mathrm{c}$ and $13 \mathrm{f}$ further indicate that $\beta$ increases with increasing urban density $\left(R^{2}=0.34\right)$ and decreasing vegetation fraction $\left(R^{2}=0.42\right)$.

The mean daytime $\Delta Q_{S} / Q^{*}$ of this study reports a lower value than that of Me93 and Sh13. This is mainly related to urban density, as $\Delta Q_{S} / Q^{*}$ increases significantly with urban density $\left(R^{2}=0.73\right)$.

From all ratios in Fig. 13, it can be found that all compared ratios vary a lot for the sites in the sub(tropical) regions, while they stay in the middle range and vary slightly for the sites in temperate regions. This is probably caused by the limited samples of the temperate regions, but it is definitely worthwhile to further analyze the SEB data in the sub(tropical) regions.

\section{e. LUMPS validation}

The performance of LUMPS were evaluated in this study by using the Linear regression method (intercept $a$, slope $b$, and coefficient of determination $R^{2}$ ), mean bias error (MBE), and root-mean-square error (RMSE) as follows:

$$
\begin{aligned}
\mathrm{MBE} & =\frac{1}{n} \sum_{i=1}^{n}\left(P_{i}-O_{i}\right), \quad \text { and } \\
\mathrm{RMSE} & =\sqrt{\frac{1}{n} \sum_{i=1}^{n}\left(P_{i}-O_{i}\right)^{2}},
\end{aligned}
$$

where $P_{i}$ are model-predicted values and $O_{i}$ are observed values. According to Willmott (1982), the statistical parameters of systematic RMSE $\left(\mathrm{RMSE}_{S}\right)$, unsystematic RMSE $\left(\operatorname{RMSE}_{U}\right)$, and the index of agreement $(d)$ were adopted as well:

$$
\begin{aligned}
\operatorname{RMSE}_{S} & =\sqrt{\frac{1}{n} \sum_{i=1}^{n}\left(P_{i}^{*}-O_{i}\right)^{2}}, \\
\operatorname{RMSE}_{U} & =\sqrt{\frac{1}{n} \sum_{i=1}^{n}\left(P_{i}^{*}-P_{i}\right)^{2}}, \quad \text { and } \\
d & =1-\frac{\sum_{i=1}^{n}\left(P_{i}-O_{i}\right)^{2}}{\sum_{i=1}^{n}\left(\left|P_{i}^{\prime}\right|+\left|O_{i}^{\prime}\right|\right)^{2}}, \quad(0 \leq d \leq 1),
\end{aligned}
$$

where $P_{i}^{*}=a+b O_{i}, a$ and $b$ are the least squares regression coefficients of $P_{i}$ and $O_{i}, P_{i}^{\prime}=P_{i}-\bar{O}, O_{i}^{\prime}=O_{i}-\bar{O}$, and 


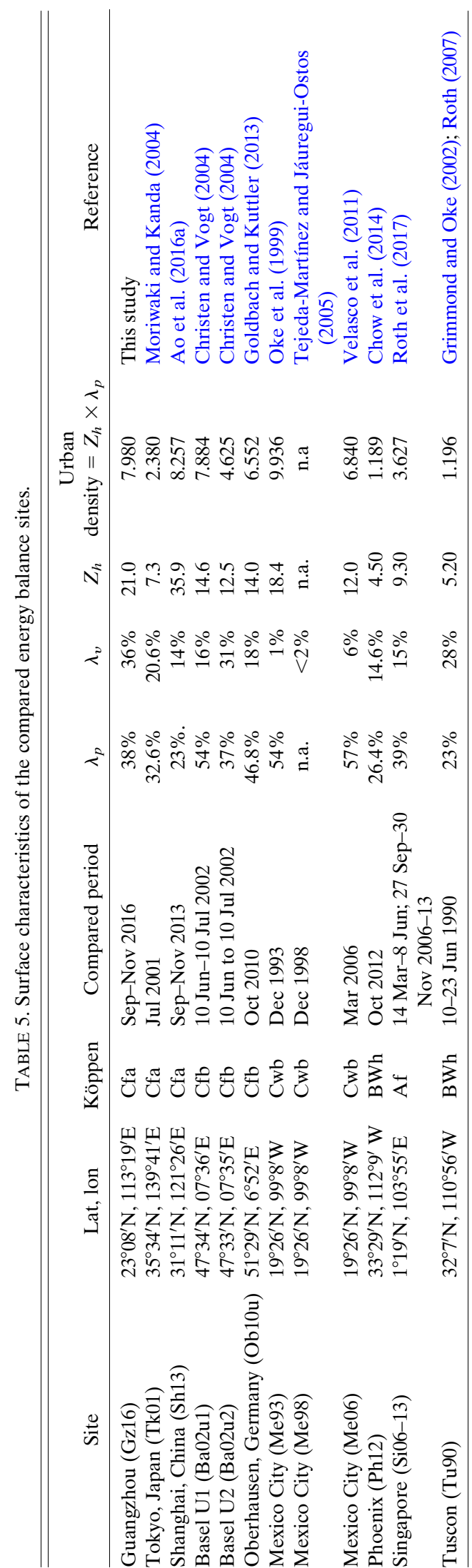

$\bar{O}$ is the mean value of the observed. The value of RMSE should be minimized so that the model is predicting at peak accuracy. Concerning a "good" model, the magnitude of RMSEs should approach zero, whereas the value of $R_{M S E}$ should approach RMSE (Stunder and Sethuraman 1986). A value of $d$ close to 1.0 indicates that the model prediction approaches the observed variable.

\section{1) Net ALL-WAVE RADiATiON}

$Q^{*}$ can be obtained easily from parameterization using measured or modeled solar radiation (Newton et al. 2007). We derived it from the NARP (Offerle et al. 2003) as Loridan et al. (2011) does. The observed $L \downarrow$ was used in NARP model since it has the best performance to calculate $Q^{*}$ based on the evaluation of Loridan et al. (2011). The surface albedo $\alpha$ and emissivity $\varepsilon$ were set as 0.08 and 0.98 for vegetation, 0.12 and 0.91 for paved road, and 0.15 and 0.95 for buildings, respectively.

Comparison of the observed and modeled $Q^{*}$ are plotted in Figs. 14a and 14e and the statistics are shown in Table 6 . The use of NARP to model $Q^{*}$ yields a good performance with a high $R^{2}$ and relatively low MBE and RMSE. This corresponds well to the fact that all the scatter points are close to the line $y=x$ in Fig. 14a, and two lines in Fig. 14e were overlapped.

\section{2) Storage HeAt FLuX}

The storage heat flux $\left(\Delta Q_{S}\right)$ is very difficult to measure directly (Grimmond and Oke 1999b), requiring extensive observations that cover the diversity of buildings, canyons, and other elements of the urban canopy volume. Hence, it is usually measured as the residual term $\left(Q_{\mathrm{RES}}\right)$ of the SEB or predicted by using the objective hysteresis model (OHM) (Grimmond et al. 1991; Grimmond and Oke 1999b) as LUMPS does. The OHM equation is

$\Delta Q_{S}=\sum_{i=1}^{n}\left(f_{i} a_{1 i}\right) Q^{*}+\sum_{i=1}^{n}\left(f_{i} a_{2 i}\right)\left(\frac{\partial Q^{*}}{\partial t}\right)+\sum_{i=1}^{n}\left(f_{i} a_{3 i}\right)$,

where $f_{i}$ is the fraction of each of the $i$ surface types, $a_{1}$ is the coefficient of the direct relation between $\Delta Q_{S}$ and $Q^{*}, a_{2}$ is the coefficient accounts for hysteresis between $\Delta Q_{S}$ and $Q^{*}$, and $a_{3}$ is an intercept term.

In the present study, we classified the land surfaces into three types following LUMPS and obtained the fractions for vegetation, impervious surfaces, and rooftops as $36 \%, 26 \%$, and $38 \%$, respectively, according to the GIS database of the study site. The OHM coefficient of average vegetation was used for vegetation, that of Doll et al. (1985) was used for impervious surfaces, and that of concrete was provided by Asaeda and Ca (1993) for rooftops. 

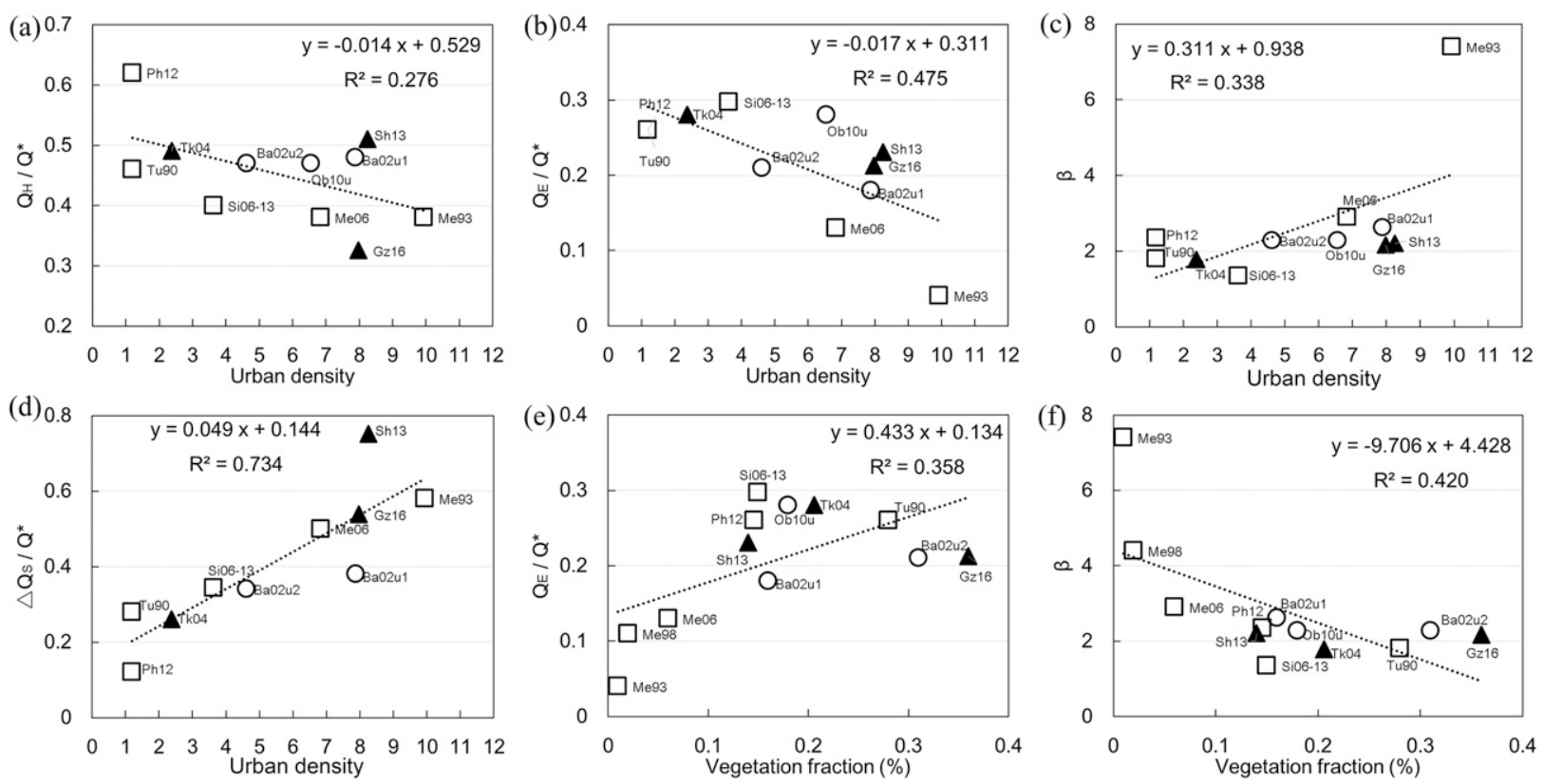

FIG. 13. The mean daytime (a) $Q_{H} / Q^{*}$, (b) $Q_{E} / Q^{*}$, (c) $\beta$, and (d) $\Delta Q_{S} / Q^{*}$ changed with the urban density. The average daytime (e) $Q_{E} / Q^{*}$ and (f) $\beta$ as a function of the vegetation fraction. Samples are from these study sites of the sub(tropical) regions (square), temperate regions (circle), and the humid subtropical regions (filled triangle).

$\Delta Q_{S}$ was predicted using OHM and compared with the measured $Q_{\mathrm{RES}}$, as Figs. $14 \mathrm{~b}$ and $14 \mathrm{f}$ show. The predicted and measured values have a highly positive correlation, with $R^{2}$ of 0.839 and $d$ of 0.951 . However, the scatter points are biased to the line $y=x$ to a certain extent, and RMSE is $59.6 \mathrm{~W} \mathrm{~m}^{-2}$, so the results are considered barely satisfactory. The influence of day and night is clear (Table 6), where the values of $R^{2}$ and $d$ for daytime are relatively higher than those of nighttime.

\section{3) Sensible And Latent heat FluXes}

In LUMPS, the turbulent fluxes of sensible and latent heat were calculated using the following equations:

$$
\begin{aligned}
Q_{H} & =\frac{(1-\alpha)+(\gamma / s)}{1+(\gamma / s)}\left(Q^{*}-\Delta Q_{S}\right)-\beta, \text { and } \\
Q_{E} & =\frac{\alpha}{1+(\gamma / s)}\left(Q^{*}-\Delta Q_{S}\right)+\beta,
\end{aligned}
$$

where $s$ is the slope of the saturation vapor pressure versus temperature curve in $\mathrm{Pa}^{\circ} \mathrm{C}^{-1}, \gamma$ is the psychrometric constant, and $\alpha$ and $\beta$ are empirical parameters. The empirical parameters were obtained using the regression method by Grimmond and Oke (2002).

The performances of the modeled $Q_{H}$ and $Q_{E}$ when using LUMPS were tested by comparison with the field observations, as shown in Table 6 and Figs. 14c,d,g,h. The overall RMSE are $36.5 \mathrm{~W} \mathrm{~m}^{-2}$ for $Q_{H}$ and $42.8 \mathrm{~W} \mathrm{~m}^{-2}$ for $Q_{E}$. From Figs. $14 \mathrm{~g}$ and $14 \mathrm{~h}$, it can be seen that $Q_{H}$ is overestimates except for the maxima in daytime, and $Q_{E}$ is underestimated both day and night. This agrees with the study of Loridan et al. (2011) showing that LUMPS would benefit from a more accurate partitioning of the available energy between the two turbulent processes. The statistics of $R^{2}$ and $d$ values for nighttime are lower than those of daytime both for $Q_{H}$ and $Q_{E}$, indicating that the performance is better for daytime. The RMSE ${ }_{S}$ of $Q_{E}$ is larger than its $\mathrm{RMSE}_{U}$ for all cases, indicating a large error in the modeled $Q_{E}$ by LUMPS.

The present results were compared with the evaluation of LUMPS at cities of Łódź, Poland (Loridan et al. 2011), and Shanghai (Ao et al. 2017). The RMSE of $Q_{H}$ ranges from 30 to $39 \mathrm{~W} \mathrm{~m}^{-2}$ for Łódź, and from 47.2 to $115.7 \mathrm{~W} \mathrm{~m}^{-2}$ for Shanghai. The value of this study $\left(36.5 \mathrm{~W} \mathrm{~m}^{-2}\right)$ is close to that of Łódź. In terms of RMSE of $Q_{E}$, the result of this study $\left(42.8 \mathrm{~W} \mathrm{~m}^{-2}\right)$ is slightly larger than that of Łódź (from 21.6 to $32.9 \mathrm{~W} \mathrm{~m}^{-2}$ ) and within the range of Shanghai (from 17.1 to $53.1 \mathrm{~W} \mathrm{~m}^{-2}$ ). Models of anthropogenic energy usage, irrespective of water balance, the net advection of heat and moisture into/out of the area, and some other sinks (sources), are among the possible reasons for such a bias of LUMPS.

\section{Conclusions}

In the present study, local-scale urban energy balance observations were conducted in Guangzhou from September to November of 2016, and the adaptability of 

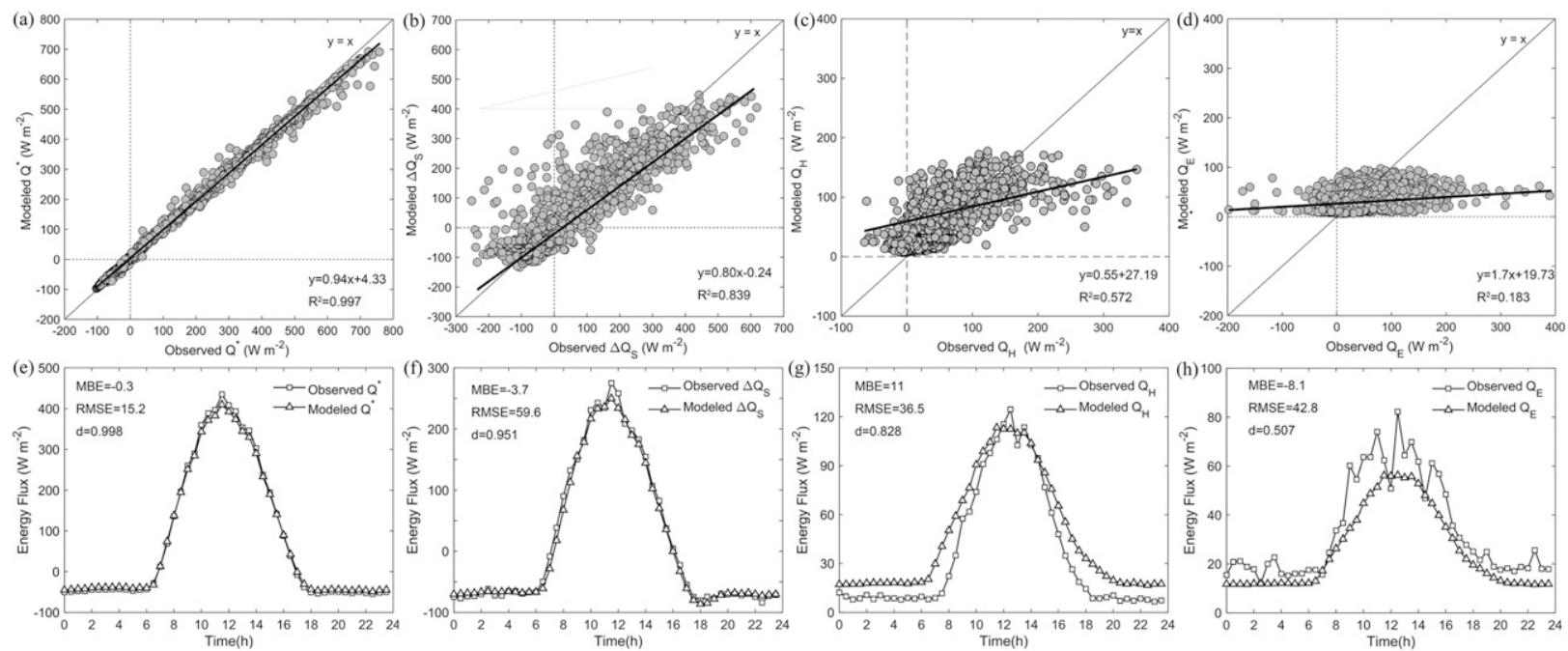

FIG. 14. Observed vs modeled (a) $Q^{*}$, (b) $\Delta Q_{S}$, (c) $Q_{H}$, and (d) $Q_{E}$. The linear regression with solid lines is shown. Diurnal mean observed and modeled (e) $Q^{*}$, (f) $\Delta Q_{S}$, (g) $Q_{H}$, and (h) $Q_{E}$. MBE, RMSE, and $d$ statistics are given.

LUMPS in the humid subtropical region was validated using the field observations. The following conclusions were obtained.

The study site is a typical local-scale urban residential area in a humid subtropical region and contains two representative LCZ types of central Guangzhou, with a building density of $38 \%$, vegetation coverage of $36 \%$, mean building height of $21 \mathrm{~m}$, roughness length of $2.3 \mathrm{~m}$, and zero-plane displacement of $13.5 \mathrm{~m}$. The observations were conducted at the center of the site at a height of $110 \mathrm{~m}$, with a radius of $330 \mathrm{~m}$ for the $90 \%$ view factor of the radiation source area, and distances of nearly $1000 \mathrm{~m}$ and over $1000 \mathrm{~m}$ for the $50 \%$ turbulent source area with the main wind direction of northwest under various atmospheric conditions.

For the whole study period, the median solar radiation values were positive in daytime and zero at night, with the daily maxima of $K \downarrow$ ( $K \uparrow)$ from 200 (20) to 1000 (120) $\mathrm{W} \mathrm{m}^{-2}$ occurring at noon. The median longwave radiations always remained positive, with the daily maxima of $L \downarrow$ ( $L \uparrow)$ from 280 (360) to $460(530) \mathrm{W} \mathrm{m}^{-2}$ occurring after noon. The median diurnal pattern of $Q^{*}$ was similar to that of $K \downarrow$ except for being negative at nighttime, with daily maxima from 200 to $800 \mathrm{~W} \mathrm{~m}^{-2}$. The diurnal pattern of surface albedo showed a general U shape, with most of the daytime being nearly 0.12 and higher values in the early morning and late afternoon, suggesting an increasing surface albedo with a smaller solar elevation.

For the whole study period, the median $Q_{H}$ was not less than zero even during nighttime, and its daily maximum was $118 \mathrm{~W} \mathrm{~m}^{-2}$. The median $Q_{E}$ exhibited a diurnal variation gentler than that of $Q_{H}$, with a median daily maximum of $66 \mathrm{~W} \mathrm{~m}^{-2}$. The median $\beta$ was larger than one during most of the daytime and lower than one at night, suggesting a dominant role of $Q_{H}$ in the daytime and of $Q_{E}$ at night. The median diurnal pattern of $\Delta Q_{S}$ was similar to that of $Q^{*}$, with daily maxima of $287 \mathrm{~W} \mathrm{~m}^{-2}$.

TABLE 6. Statistical results for measured vs modeled $Q^{*}, \Delta Q_{S}, Q_{H}$, and $Q_{E}$.

\begin{tabular}{|c|c|c|c|c|c|c|c|c|c|c|}
\hline Variable & Conditions & Number & Slope & Intercept & $R^{2}$ & MBE & RMSE & $\mathrm{RMSE}_{S}$ & $\operatorname{RMSE}_{U}$ & $d$ \\
\hline \multirow[t]{3}{*}{$Q^{*}$} & Overall & 2315 & 0.94 & 4.33 & 0.997 & -0.3 & 15.2 & 11.0 & 10.6 & 0.998 \\
\hline & Daytime & 1169 & 0.93 & 7.54 & 0.994 & -6.1 & 20.5 & 15.5 & 14.4 & 0.997 \\
\hline & Nighttime & 1146 & 0.96 & 3.84 & 0.988 & 5.7 & 6.4 & 5.9 & 2.6 & 0.983 \\
\hline \multirow[t]{3}{*}{$\Delta Q_{S}$} & Overall & 2315 & 0.80 & -0.24 & 0.839 & -3.7 & 59.6 & 30.2 & 51.3 & 0.951 \\
\hline & Daytime & 1169 & 0.74 & 19.83 & 0.771 & -8.9 & 78.0 & 42.6 & 64.8 & 0.928 \\
\hline & Nighttime & 1146 & 0.25 & -52.16 & 0.278 & 1.5 & 31.4 & 27.7 & 15.1 & 0.621 \\
\hline \multirow[t]{3}{*}{$Q_{H}$} & Overall & 2315 & 0.55 & 27.19 & 0.572 & 11.0 & 36.5 & 26.1 & 25.3 & 0.828 \\
\hline & Daytime & 1169 & 0.41 & 48.83 & 0.455 & 11.7 & 47.7 & 38.5 & 27.8 & 0.749 \\
\hline & Nighttime & 1146 & 0.12 & 18.31 & 0.075 & 10.4 & 19.3 & 18.0 & 7.0 & 0.489 \\
\hline \multirow[t]{3}{*}{$Q_{E}$} & Overall & 2315 & 0.17 & 19.73 & 0.183 & -8.1 & 42.8 & 39.0 & 17.0 & 0.507 \\
\hline & Daytime & 1169 & 0.11 & 32.69 & 0.112 & -10.1 & 54.0 & 50.7 & 18.2 & 0.419 \\
\hline & Nighttime & 1146 & 0.01 & 12.55 & 0.01 & -6.1 & 27.3 & 27.2 & 3.1 & 0.236 \\
\hline
\end{tabular}


The sky conditions played a significant part in the urban surface energy exchanges. The median daily maxima of $Q^{*}, Q_{H}, \Delta Q_{S}$, surface albedo, and $\beta$ all present a consistent order from large to small for clear, cloudy, and rainy days because those variables are greatly influenced by the incoming solar radiation, which changes with the sky conditions in the same order. $Q_{E}$ shows a different order from large to small for rainy, clear, and cloudy days, suggesting that not only abundant rainfall but also strong radiation and high air temperature promote evaporation. The magnitude of $L \downarrow$ on rainy and cloudy days is larger than that of clear days, showing $L \downarrow$ as a function of cloud cover.

The present study discovers some features different from those obtained in dry sub(tropical) climates or temperate regions. The daily maxima of $K \downarrow$ vary more than that of London and Shanghai, and the daytime surface albedo is smaller than that of Los Angeles and Chicago. The mean daytime proportion of $Q^{*}$ dissipated by $Q_{H}$ is smaller than most of the other sites, because a high urban density could cause a large $\Delta Q_{S}$ within the canopy and reduce upward-directed $Q_{H}$. The proportion of $Q^{*}$ dissipated by $Q_{E}$ is larger than that of hot desert climate sites. The mean daytime $Q_{E} / Q^{*}$ and $\beta$ are functions of both vegetation fraction and urban density.

The adaptabilities of NARP, OHM, and LUMPS to the humid subtropical region were confirmed by comparison with field observations. For the whole study period, the predicted $Q^{*}$ and $\Delta Q_{S}$ have highly positive correlations with their measured values, showing an index of agreement higher than 0.95. The RMSE values of $Q_{H}$ and $Q_{E}$ are 36.5 and $42.8 \mathrm{~W} \mathrm{~m}^{-2}$, falling within an acceptable range by comparing the validations by Loridan et al. (2011) and Ao et al. (2017).

In the present study, local-scale urban energy balance observations under various sky conditions in the humid subtropical region are presented. The results help us verify and improve parameterizations of the energy exchange over urban surfaces in this region and can be practically beneficial when guiding urban planning and resilient urban designs.

Acknowledgments. This work has been supported by the National Natural Science Foundation of China (Grant 51578243).

\section{REFERENCES}

Aida, M., 1982: Urban albedo as a function of the urban structureA model experiment. Bound.-Layer Meteor., 23, 405-413, https://doi.org/10.1007/BF00116269.

Allen, L., F. Lindberg, and C. S. B. Grimmond, 2011: Global to city scale urban anthropogenic heat flux: Model and variability. Int. J. Climatol., 31, 1990-2005, https://doi.org/10.1002/joc.2210.
Ando, T., and M. Ueyama, 2017: Surface energy exchange in a dense urban built-up area based on two-year eddy covariance measurements in Sakai, Japan. Urban Climate, 19, 155-169, https://doi.org/10.1016/j.uclim.2017.01.005.

Ao, X., and Coauthors, 2016a: Heat, water and carbon exchanges in the tall megacity of Shanghai: Challenges and results. Int. J. Climatol., 36, 4608-4624, https://doi.org/10.1002/joc.4657.

- C. S. B. Grimmond, D. Liu, Z. Han, P. Hu, Y. Wang, X. Zhen, and J. Tan, 2016b: Radiation fluxes in a business district of Shanghai, China. J. Appl. Meteor. Climatol., 55, 2451-2468, https://doi.org/10.1175/JAMC-D-16-0082.1.

- J. Tan, D. Liu, Y. Wang, and P. Hu, 2017: Evaluation of a surface urban energy balance model in Shanghai (in Chinese). Meteor. Mon., 43, 973-986.

Arnfield, A. J., 2003: Two decades of urban climate research: A review of turbulence, exchanges of energy and water, and the urban heat island. Int. J. Climatol., 23, 1-26, https://doi.org/ 10.1002/joc.859.

Asaeda, T., and V. T. Ca, 1993: The subsurface transport of heat and moisture and its effect on the environment: A numerical model. Bound.-Layer Meteor., 65, 159-179, https://doi.org/ 10.1007/BF00708822.

Baldocchi, D., and Coauthors, 2001: FLUXNET: A new tool to study the temporal and spatial variability of ecosystem-scale carbon dioxide, water vapor, and energy flux densities. Bull. Amer. Meteor. Soc., 82, 2415-2434, https://doi.org/10.1175/ 1520-0477(2001)082<2415:FANTTS > 2.3.CO;2.

Batchvarova, E., and S. E. Gryning, 1991: Applied model for the growth of the daytime mixed layer. Bound.-Layer Meteor., 56, 261-274, https://doi.org/10.1007/BF00120423.

Bottema, M., 1995: Parameterisation of aerodynamic roughness parameters in relation to air pollutant removal efficiency of streets. Air Pollut. Eng. Manage., 6, 235-242.

_ 1997: Urban roughness modelling in relation to pollutant dispersion. Atmos. Environ., 31, 3059-3075, https://doi.org/ 10.1016/S1352-2310(97)00117-9.

Campbell, G. S., and J. M. Norman, 1998: An Introduction to Environmental Biophysics. 2nd ed. Springer, 286 pp.

Chow, W. T. L., T. J. Volo, E. R. Vivoni, G. D. Jenerette, and B. L. Ruddell, 2014: Seasonal dynamics of a suburban energy balance in Phoenix, Arizona. Int. J. Climatol., 34, 3863-3880, https://doi.org/10.1002/joc.3947.

Christen, A., and R. Vogt, 2004: Energy and radiation balance of a central European city. Int. J. Climatol., 24, 1395-1421, https:// doi.org/10.1002/joc.1074.

Doll, D., J. K. S. Ching, and J. Kaneshiro, 1985: Parameterization of subsurface heating for soil and concrete using net radiation data. Bound.-Layer Meteor., 32, 351-372, https://doi.org/ 10.1007/BF00122000.

Dou, J., S. Grimmond, Z. Cheng, S. Miao, D. Feng, and M. Liao, 2019: Summertime surface energy balance fluxes at two Beijing sites. Int. J. Climatol., 39, 2793-2810, https://doi.org/10.1002/joc.5989.

Duffie, J. A., and W. A. Beckman, 2013: Solar Engineering of Thermal Processes. Wiley, $910 \mathrm{pp}$.

Flerchinger, G. N., W. Xaio, D. Marks, T. J. Sauer, and Q. Yu, 2009: Comparison of algorithms for incoming atmospheric longwave radiation. Water Resour. Res., 45, W03423, https://doi.org/ 10.1029/2008WR007394.

Foken, T., M. Göockede, M. Mauder, L. Mahrt, B. Amiro, and W. Munger, 2004: Post-field data quality control. Handbook of Micrometeorology: A Guide for Surface Flux Measurement and Analysis, X. Lee, W. Massman, and B. Law, Eds., Kluwer Academic Publishers, 181-208. 
Goldbach, A., and W. Kuttler, 2013: Quantification of turbulent heat fluxes for adaptation strategies within urban planning. Int. J. Climatol., 33, 143-159, https://doi.org/10.1002/joc.3437.

Grimmond, C. S. B., and T. R. Oke, 1999a: Aerodynamic properties of urban areas derived from analysis of surface form. J. Appl. Meteor., 38, 1262-1292, https://doi.org/10.1175/15200450(1999)038<1262:APOUAD > 2.0.CO;2.

, and -1999 b: Heat storage in urban areas: Local-scale observations and evaluation of a simple model. J. Appl. Meteor., 38, 922-940, https://doi.org/10.1175/1520-0450(1999) $038<0922:$ HSIUAL $>2.0$. CO; 2 .

$\longrightarrow$, and — 2002: Turbulent heat fluxes in urban areas: Observations and a local-scale urban meteorological parameterization scheme (LUMPS). J. Appl. Meteor., 41, 792-810, https://doi.org/10.1175/1520-0450(2002)041<0792:THFIUA $>$ 2.0.CO;2.

- H. A. Cleugh, and T. R. Oke, 1991: An objective urban heat storage model and its comparison with other schemes. Atmos. Environ., 25B, 311-326, https://doi.org/10.1016/0957-1272(91) 90003-W.

— ance Models Comparison Project: First results from phase 1. J. Appl. Meteor. Climatol., 49, 1268-1292, https://doi.org/ 10.1175/2010JAMC2354.1.

— , and Coauthors, 2011: Initial results from phase 2 of the international urban energy balance model comparison. Int. J. Climatol., 31, 244-272, https://doi.org/10.1002/joc.2227.

Järvi, L., C. S. B. Grimmond, and A. Christen, 2011: The Surface Urban Energy and Water Balance Scheme (SUEWS): Evaluation in Los Angeles and Vancouver. J. Hydrol., 411, 219-237, https://doi.org/10.1016/j.jhydrol.2011.10.001.

Kaimal, J., and J. Finnigan, 1994: Atmospheric Boundary Layer Flows-Their Structure and Measurement. Oxford University Press, 289 pp.

Kawai, T., and M. Kanda, 2010: Urban energy balance obtained from the Comprehensive Outdoor Scale Model Experiment. Part I: Basic features of the surface energy balance. J. Appl. Meteor. Climatol., 49, 1341-1359, https://doi.org/10.1175/ 2010JAMC1992.1.

Kljun, N., M. W. Rotach, and H. P. Schmid, 2002: A three-dimensional backward Lagrangian footprint model for a wide range of boundary-layer stratifications. Bound.-Layer Meteor., 103, 205226, https://doi.org/10.1023/A:1014556300021.

—, P. Calanca, M. W. Rotach, and H. P. Schmid, 2015: The simple two-dimensional parameterisation for Flux Footprint Prediction (FFP). Geosci. Model Dev., 8, 3695-3713, https:// doi.org/10.5194/gmd-8-3695-2015.

Kormann, R., and F. X. Meixner, 2001: An analytical footprint model for non-neutral stratification. Bound.-Layer Meteor., 99, 207-224, https://doi.org/10.1023/A:1018991015119.

Kotthaus, S., and C. S. B. Grimmond, 2012: Identification of micro-scale anthropogenic $\mathrm{CO}_{2}$, heat and moisture sources-Processing eddy covariance fluxes for a dense urban environment. Atmos. Environ., 57, 301-316, https://doi.org/ 10.1016/j.atmosenv.2012.04.024.

$\longrightarrow$, and — 2014a: Energy exchange in a dense urban environment-Part I: Temporal variability of long-term observations in central London. Urban Climate, 10, 261-280, https:// doi.org/10.1016/j.uclim.2013.10.002.

, and,$- 2014 \mathrm{~b}$ : Energy exchange in a dense urban environment-Part II: Impact of spatial heterogeneity of the surface. Urban Climate, 10, 281-307, https://doi.org/10.1016/ j.uclim.2013.10.001.
Lee, X., W. Massman, and B. Law, Eds., 2006: Handbook of Micrometeorology: A Guide for Surface Flux Measurement and Analysis. Kluwer Academic Publishers, 250 pp.

Liu, H., G. Peters, and T. Foken, 2001: New equations for sonic temperature variance and buoyancy heat flux with an omnidirectional sonic anemometer. Bound.-Layer Meteor., 100, 459-468, https://doi.org/10.1023/A:1019207031397.

Liu, H. Z., G. Tu, and W. J. Dong, 2008: Three-year changes of surface albedo of degraded grassland and cropland surfaces in a semiarid area. Chin. Sci. Bull., 53, 1246-1254, https:// doi.org/10.1007/s11434-008-0171-2.

_ J. W. Feng, L. Järvi, and T. Vesala, 2012: Four-year (20062009) eddy covariance measurements of $\mathrm{CO}_{2}$ flux over an urban area in Beijing. Atmos. Chem. Phys., 12, 7881-7892, https://doi.org/10.5194/acp-12-7881-2012.

Loridan, T., C. Grimmond, B. D. Offerle, D. T. Young, T. E. L. Smith, L. Järvi, and F. Lindberg, 2011: Local-Scale Urban Meteorological Parameterization Scheme (LUMPS): Longwave radiation parameterization and seasonality-related developments. J. Appl. Meteor. Climatol., 50, 185-202, https:// doi.org/10.1175/2010JAMC2474.1.

Lucht, W., C. B. Schaaf, and A. H. Strahler, 2000: An algorithm for the retrieval of albedo from space using semiempirical BRDF models. IEEE Trans. Geosci. Remote Sens., 38, 977-998, https://doi.org/10.1109/36.841980.

Macdonald, R. W., R. F. Griffiths, and D. J. Hall, 1998: An improved method for the estimation of surface roughness of obstacle arrays. Atmos. Environ., 32, 1857-1864, https:// doi.org/10.1016/S1352-2310(97)00403-2.

Martilli, A., A. Clappier, and M. W. Rotach, 2002: An urban surface exchange parameterisation for mesoscale models. Bound.-Layer Meteor., 104, 261-304, https://doi.org/ 10.1023/A:1016099921195.

Massman, W. J., 2000: A simple method for estimating frequency response corrections for eddy covariance systems. Agric. For. Meteor., 104, 185-198, https://doi.org/10.1016/S0168-1923(00) 00164-7.

Miao, S. G., J. X. Dou, C. Fei, L. Ju, and A. G. Li, 2012: Analysis of observations on the urban surface energy balance in Beijing. Sci. China Earth Sci., 55, 1881-1890, https://doi.org/10.1007/ s11430-012-4411-6.

Moriwaki, R., and M. Kanda, 2004: Seasonal and diurnal fluxes of radiation, heat, water vapor, and carbon dioxide over a suburban area. J. Appl. Meteor., 43, 1700-1710, https://doi.org/10.1175/JAM2153.1.

Nemitz, E., K. J. Hargreaves, A. G. Mcdonald, J. R. Dorsey, and D. Fowler, 2002: Micrometeorological measurements of the urban heat budget and $\mathrm{CO} 2$ emissions on a city scale. Environ. Sci. Technol., 36, 3139-3146, https://doi.org/10.1021/es010277e.

Newton, T., T. R. Oke, C. S. B. Grimmond, and M. Roth, 2007: The suburban energy balance in Miami, Florida. Geogr. Ann., 89A, 331-347, https://doi.org/10.1111/j.1468-0459.2007.00329.x.

Nieuwstadt, F. T. M., 1981: The steady-state height and resistance laws of the nocturnal boundary layer: Theory compared with Cabauw observations. Bound.-Layer Meteor., 20, 3-17, https:// doi.org/10.1007/BF00119920.

Offerle, B., C. S. B. Grimmond, and T. R. Oke, 2003: Parameterization of net all-wave radiation for urban areas. J. Appl. Meteor., 42, 1157-1173, https://doi.org/10.1175/1520-0450(2003)042<1157: PONARF $>2.0 . \mathrm{CO} ; 2$.

Oke, T. R., 1987: Boundary Layer Climates. 2nd ed. Routledge, 435 pp.

, 2006: Initial guidance to obtain representative meteorological observations at urban sites. Instruments and Observing Methods 
Rep. 81, WMO/TD 1250, 51 pp., http://library.wmo.int/pmb_ged/ wmo-td_1250.pdf.

— , R. A. Spronken-Smith, E. Jáuregui, and C. S. B. Grimmond, 1999: The energy balance of central Mexico City during the dry season. Atmos. Environ., 33, 3919-3930, https://oi.org/ 10.1016/S1352-2310(99)00134-X.

_- G. Mills, A. Christen, and J. A. Voogt, 2017: Urban Climates. Cambridge University Press, 519 pp.

Pape, R., and J. Löffler, 2004: Modelling spatio-temporal nearsurface temperature variation in high mountain landscapes. Ecol. Modell., 178, 483-501, https://doi.org/10.1016/ j.ecolmodel.2004.02.019.

Raupach, M. R., 1994: Simplified expressions for vegetation roughness length and zero-plane displacement as functions of canopy height and area index. Bound.-Layer Meteor., 71, 211-216, https://doi.org/10.1007/BF00709229.

Roth, M., 2007: Review of urban climate research in (sub)tropical regions. Int. J. Climatol., 27, 1859-1873, https://doi.org/10.1002/ joc. 1591.

_ C. Jansson, and E. Velasco, 2017: Multi-year energy balance and carbon dioxide fluxes over a residential neighbourhood in a tropical city. Int. J. Climatol., 37, https://doi.org/10.1002/joc.4873.

Schmid, H. P., 1994: Source areas for scalars and scalar fluxes. Bound.-Layer Meteor., 67, 293-318, https://doi.org/10.1007/ BF00713146.

_ 1997: Experimental design for flux measurements: matching scales of observations and fluxes. Agric. For. Meteor., 87, 179200, https://doi.org/10.1016/S0168-1923(97)00011-7.

— , and T. R. Oke, 1990: A model to estimate the source area contributing to turbulent exchange in the surface layer over patchy terrain. Quart. J. Roy. Meteor. Soc., 116, 965-988, https://doi.org/10.1002/qj.49711649409.

— H. A. Cleugh, C. S. B. Grimmond, and T. R. Oke, 1991: Spatial variability of energy fluxes in suburban terrain. Bound.-Layer Meteor., 54, 249-276, https://doi.org/10.1007/BF00183956.

Schotanus, P., F. T. M. Nieuwstadt, and H. A. R. De Bruin, 1983: Temperature measurement with a sonic anemometer and its application to heat and moisture fluxes. Bound.-Layer Meteor., 26, 81-93, https://doi.org/10.1007/BF00164332.

Stewart, I. D., and T. R. Oke, 2012: Local climate zones for urban temperature studies. Bull. Amer. Meteor. Soc., 93, 1879-1900, https://doi.org/10.1175/BAMS-D-11-00019.1.

Stunder, M., and S. Sethuraman, 1986: A statistical evaluation and comparison of coastal point source Dispersion Models. Atmos. Environ., 20, 301-315, https://doi.org/10.1016/0004-6981(86) 90032-6.

Tejeda-Martínez, A., and E. Jáuregui-Ostos, 2005: Surface energy balance measurements in the México City region: A review. Atmósfera, 18, 1-23.

Velasco, E., S. Pressley, R. Grivicke, E. Allwine, L. T. Molina, and B. Lamb, 2011: Energy balance in urban Mexico City: Observation and parameterization during the MILAGRO/ MCMA-2006 field campaign. Theor. Appl. Climatol., 103, 501-517, https://doi.org/10.1007/s00704-010-0314-7.

Vickers, D., and L. Mahrt, 1997: Quality control and flux sampling problems for tower and aircraft data. J. Atmos. Oceanic Technol., 14, 512-526, https://doi.org/10.1175/1520-0426(1997) $014<0512$ :QCAFSP $>2.0 . \mathrm{CO} ; 2$.

Ward, H. C., S. Kotthaus, L. Järvi, and C. S. B. Grimmond, 2016: Surface Urban Energy and Water Balance Scheme (SUEWS): Development and evaluation at two UK sites. Urban Climate, 18, 1-32, https://doi.org/10.1016/j.uclim.2016.05.001.

Webb, E. K., G. I. Pearman, and R. Leuning, 1980: Correction of flux measurements for density effects due to heat and water vapour transfer. Quart. J. Roy. Meteor. Soc., 106, 85-100, https://doi.org/10.1002/qj.49710644707.

Willmott, C. J., 1982: Some comments on the evaluation of model performance. Bull. Amer. Meteor. Soc., 63, 1309-1369, https://doi.org/ 10.1175/1520-0477(1982)063<1309:SCOTEO > 2.0.CO;2.

World Meteorological Organization, 2008: Guide to Meteorological Instruments and Methods of Observation. 7th edition. WMO, $681 \mathrm{pp}$.

Zhang, B., 1934: The distribution of four seasons in China (in Chinese). Acta Geogr. Sin., 1, 29-74. 